\title{
Quality assessment in laser welding: a critical review
}

\author{
John Stavridis ${ }^{1}$ - Alexios Papacharalampopoulos ${ }^{1} \cdot$ Panagiotis Stavropoulos $^{1}$
}

Received: 16 October 2016 / Accepted: 26 April 2017 / Published online: 29 May 2017

(C) The Author(s) 2018. This article is an open access publication

\begin{abstract}
Quality assessment methods and techniques for laser welding have been developed both in- and post-process. This paper summarizes and presents relevant studies being classified according to the technology implemented (vision, camera, acoustic emissions, ultrasonic testing (UT), eddy current technique (ECT)) for the quality inspection. Furthermore, the current review aims to map the existing modeling approaches used to correlating measured weld characteristics and defects with the process parameters. Research gaps and implications of the quality assessment in laser welding are also described, and a future outlook of the research in the particular field is provided.
\end{abstract}

Keywords Laser welding $\cdot$ Quality assessment $\cdot$ Weld defects $\cdot$ Monitoring techniques $\cdot$ Modeling

$\begin{array}{ll}\text { Abbreviations } \\ \text { AC } & \text { Alternative current } \\ \text { ANN } & \text { Artificial neural network } \\ \text { ANOVA } & \text { Analysis of variance } \\ \text { CCD } & \text { Coupled charged device } \\ \text { CMOS } & \text { Complementary metal oxide semiconductor } \\ \text { DC } & \text { Direct current } \\ \text { ECA } & \text { Eddy current array } \\ \text { ECT } & \text { Eddy current technique } \\ \text { EMAT } & \text { Electromagnetic acoustic transducers } \\ \text { FPS } & \text { Frames per second }\end{array}$

Panagiotis Stavropoulos pstavr@1ms.mech.upatras.gr

1 Laboratory for Manufacturing Systems and Automation, Department of Mechanical Engineering and Aeronautics, University of Patras, 26504 Patras, Greece

$\begin{array}{ll}\text { ICI } & \text { Inline coherent imaging } \\ \text { IR } & \text { Infrared } \\ \text { LIBS } & \text { Laser-induced breakdown spectroscopy } \\ \text { LOP } & \text { Lack of penetration } \\ \text { LSW } & \text { Laser spot welding } \\ \text { LW } & \text { Laser welding } \\ \text { NIR } & \text { Near-infrared range } \\ \text { PI } & \text { Proportional-integral } \\ \text { SVM } & \text { Support vector machine } \\ \text { ToF } & \text { Time of flight measurement } \\ \text { UT } & \text { Ultrasonic testing } \\ \text { UV } & \text { Ultraviolet } \\ \text { VIS } & \text { Visual }\end{array}$

\section{Introduction}

The use of flexible manufacturing processes, especially when it concerns joining technologies, has to be extended and established in modern manufacturing [1]. Laser welding (LW) is a joining method, with significant potential for industrial applications that are not fully exploited yet [2] and, compared with convectional welding methods, presents higher productivity, flexibility, effectiveness, and numerous more advantages, such as deeper penetration, lower distortions, and higher welding speeds [3]. For this reason, the process has met great response in industry [4]. However, LW is such a complex manufacturing process that the visually recognizable quality of the weld is affected by a number of process variables and other factors, such as defects in the material's microstructure, contaminations on the work-piece surface, and alteration on the laser beam's properties, resulting in a nonacceptable product (Fig. 1). The potential weld defects affect the mechanical properties of the welded components, and as a result, the risks of part fatigue are significantly increased. 
Fig. 1 Possible defects in laser welding [5]

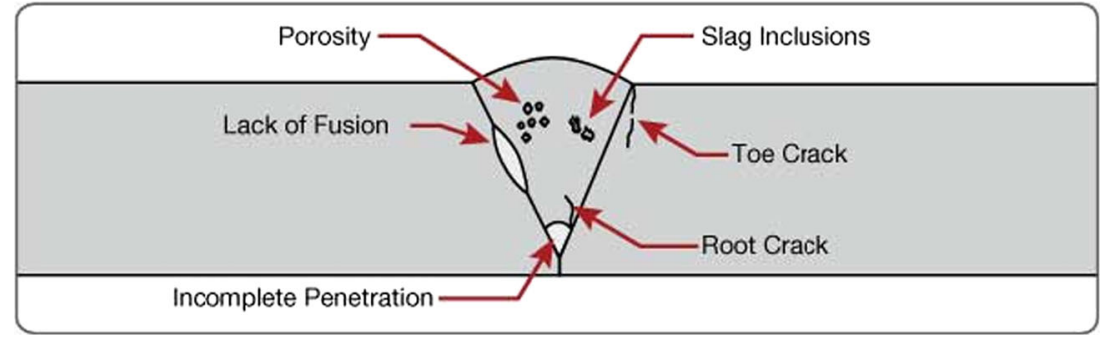

Therefore, it is important for industry to ensure that the welding seams in a product are of good quality.

Monitoring and quality control is an essential tool in modern manufacturing systems and necessary in order for production results to be kept in deterministic boundaries [6]. The monitoring of a process, and consequently, the quality assessment, follows three categories:

- Pre-process

- In-process

- Post-process

The pre-process focuses on the weld seam tracking, the in-process concerns the monitoring of the keyhole's shape stability, and the post-process mainly deals with the form of weld seam after welding (Fig. 2). In the pre- and the post-process categories, camera-based and ultrasonic solutions are dominant. Optical [visual (VIS), ultraviolet (UV), and infrared (IR)] and acoustic detectors, x-ray radiography, and camera-based solutions have been generally integrated for in-process quality inspection. In the table below, an overview of the principal quality criteria and technologies, depending on the quality assessment stage, is presented (Table 1).

The aim of this paper is to summarize the most important quality assessment techniques, found in literature, and identify potential gaps. The paper is separated into two main sections (In-process and Post-process) according to the occurrence time of monitoring and the inspection of

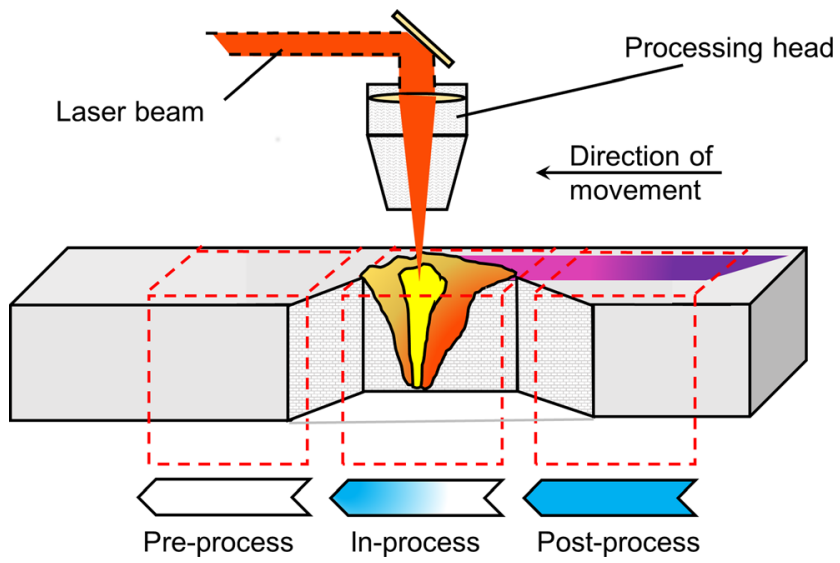

Fig. 2 Classification of monitoring stages in the time accomplished [5] laser welding. Besides, further elaboration of the papers cited herein has led to a categorization, based on the technology implemented for quality inspection. In the latter section, the authors present the modeling approaches, developed for correlation of the defects with process parameters and quality metrics. The quality assessment, as it is described in the literature, concerns the evaluation of the melt pool dimensions (penetration and bead width) and the formation of weld defects such as cracking, porosity, undercut, inclusions, and humping effect. The particular review study, based on the information extracted from the literature, suggests a future outlook for the process towards a sustainable, flexible, and modular manufacturing. Finally, Fig. 3 presents the paper's structure as it is described above and the research fields investigated herein.

\section{In-process quality assessment of laser welding}

Due to the laser-material interactions that occur during the laser welding process, energy is emitted in a variety of forms. Optical and acoustical process signals can be measured from the emissions of the welding with the use of suitable sensors. In this regard, significant information about the physical phenomena leading to the detection of welding defects can be extracted during the process. Table 2 illustrates the commonly used detectors for capturing the different laser welding signals, produced from the physical phenomena evolved in the work-piece. The reflected laser beam is the amount of the laser source's radiation, which is not absorbed by the material [8]. Hence, the developed quality assessment methods, found in literature, are based on acoustical, optical, or thermal sensors, which are often combined to improve the performance of the laser welding system.

In the following subsections, the paper presents the quality assessment methods that have been introduced, according to the monitoring technology used. Five main categories, (i) image processing techniques, (ii) acoustic emission techniques, (iii) optical signal techniques, (iv) fused sensing techniques, and (v) X-ray techniques, are investigated, and the first one is further separated into (i) thermal, (ii) vision, and (iii) combined camera-oriented techniques. The latter categorization performed on the basis of information (temperature field or spatial measurements) is provided from the cameras. 
Table 1 Quality criteria and technologies used for inspection

\begin{tabular}{ccc}
\hline Quality assessment stage & Principal quality criteria & Technology \\
\hline Pre-process & $\begin{array}{c}\text { Seam tracking, clamping, } \\
\text { gap, part geometry }\end{array}$ & Machine vision \\
Weld defects, melt pool & Plasma monitoring, keyhole and melt pool \\
In-process & camera, spectroscopy, acoustic emissions, \\
& Weld geometry, visible defects & $\begin{array}{c}\text { Machine vision, ultrasonic testing, visual } \\
\text { inspection, ECT }\end{array}$ \\
Post-process & & \\
\end{tabular}

Prior to further investigation into the quality assessment approaches, a description of the main laser welding defect formation mechanism is cited below aiming to provide a view as to the way the process parameters affect the creation of a defect and what kinds of physical phenomena need to be monitored for the estimation of critical quality measures.

Formation mechanism of weld defects The formation mechanism of defects in the melt pool during the laser welding operations has widely concerned researchers not only from the manufacturing sector but also from the material and physics sciences. Acknowledging the causes that lead to the creation of abnormalities in the molten zone is an important aspect when quality is acquired in laser welding. The published studies have also assisted other authors in examining more effectively the relationship of sensing data with the creation of weld defects. In this section, a review of the particular studies has been included, aiming to provide knowledge that will introduce the reader to the following subsections.

Pore formation, during the laser beam welding of die-cast magnesium alloy, was investigated in [9]. The paper aimed at identifying both the mechanism of pore formation and a remedy to this problem. According to their conclusions, the coalescence and expansion of small preexisting pores, due to heating and the reduction in plasma plume pressure, have contributed to the increment of porosity in the fusion zone. Additionally, the stability of the keyhole was not a major factor in the formation of the pore and the amount of porosity in the fusion zone decreased with a decrease in the heat input. Finally, well-controlled re-melting of the fusion zone allowed some of the pores to be eliminated, resulting in reduced porosity. Authors in [10] have also examined the porosity during the laser welding of aluminum alloys. With the alteration of the process parameters, the authors concluded that the macroporosity in the welds had resulted from the instability of the

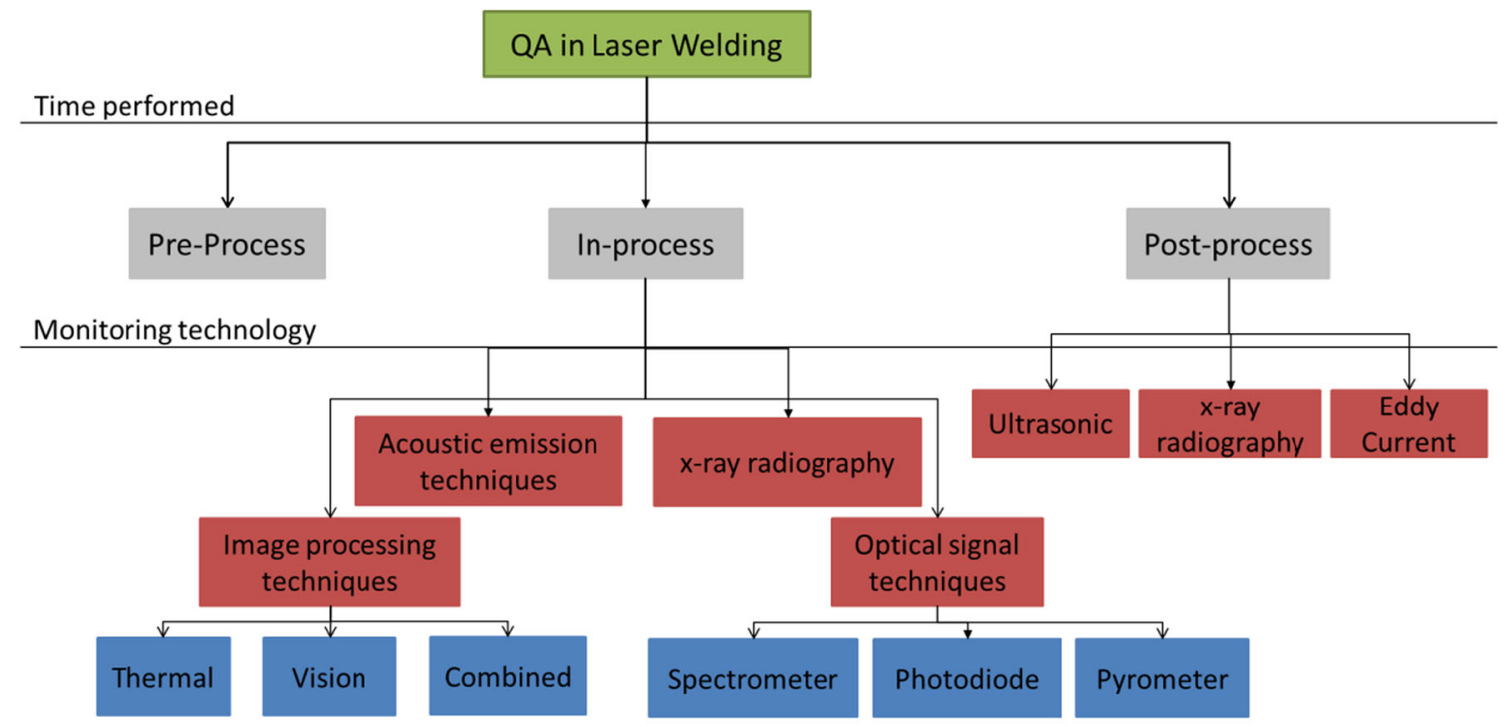

Correlating quality metrics with process parameters

Fig. 3 Paper's structure

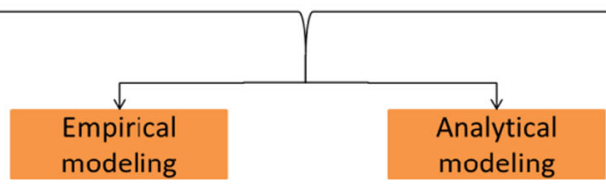


Table 2 Type of detectors used for laser welding phenomena

\begin{tabular}{ll}
\hline Phenomenon & $\begin{array}{l}\text { Commonly used types } \\
\text { of detectors }\end{array}$ \\
\hline $\begin{array}{l}\text { Emission from vapor or } \\
\text { plasma plume }\end{array}$ & Photodiode (UV, VIS), camera \\
$\begin{array}{l}\text { Emission from melt pool } \\
\text { Acoustic emission }\end{array}$ & Photodiode (VIS, IR), camera \\
Electrical charge or plasma plume & AE detectors \\
Back scattered laser radiation & Charge collecting device \\
\hline
\end{tabular}

keyhole. The collapse of the keyhole was too quick to allow the molten metal to flow into the center of the keyhole before the realization of solidification. Moreover, the instability of the keyhole and the pore formation could be minimized by controlling the laser beam defocusing and the welding speed. With respect to underfill, the authors observed that it was a recurrent defect at the root of full-penetration welds. More studies that have experimentally identified the relation of process parameters, penetration and porosity formation, have also been described in [11] and [12], ending up with similar conclusions. Finally, it has been cited that pores both on the surface and inside the material have been detected with the use of photodiodes [13], spectrometers [14], high-speed cameras $[13,15]$, and $\mathrm{x}$-ray devices [15]. In some cases, the aforementioned monitoring techniques with the implementation of signal and image processing algorithms were capable of identifying pores up to $200 \mu \mathrm{m}$ [16].

On the other hand, Sheikhi [17] and Lippold [18] investigated into the clear mechanism of the hot cracking phenomenon. As it was reported in [17], most forms of cracking resulted from the shrinkage strains that occurred as the weld metal was cooling down. There are two opposing forces: the stresses induced by the shrinkage of the metal, and the surrounding rigidity of the base material. The shrinkage stresses increase as the volume of the shrinking metal increases. Furthermore, an intentionally simple model was established. The model indicated that there is a relation between the solidification rate and the vulnerable zone length that controls the susceptibility to solidification cracking. It was demonstrated that a higher solidification rate resulted in a higher-volume change rate and a decreasing vulnerable zone length led to an increase in the liquid flow rate. Consequently, for the removal of the solidification cracks, when the solidification rate is high, more liquid flow rate or small vulnerable zone length is required. On the same pattern, but focusing on the material's microstructure, the authors in [19] among the others came up with the conclusion that the solidification cracking was found to be primarily a function of composition, while a solidification model that related to the transition in primary solidification, from ferrite to austenite to dendrite tip under-cooling, at high solidification growth rates, was discussed. Furthermore, according to [20], pulsed lasers have an influence on hot cracking over the parametric range examined.

Despite the aforementioned important defects, another effect is usually observed during laser welding. When the weld metal forms humps, above the surface level of the work-piece, the humping effect occurs. It can be noticed at high speeds, while the weld pool shape plays a significant role in the formation of humping. As it was explained in [21], the governing quantity of the humping phenomenon is the width-to-length ratio of the weld pool. It has to remain below the critical value for the occurrence of humping while the increase in the ratio can prevent humping. Moreover, the surface tension of the liquid metal has an effect only on its kinetic behavior and not on the onset of humping. In addition, since the length of the weld pool slightly decreases with an increase in the travel speed, the spacing between the humps, once established, should not be sensitive to the travel speed. However, authors in [22] have identified and studied another kind of droplet formation phenomenon during laser welding. According to the authors' opinion, the formation mechanism behind the top surface humping is considered being widely understood, but the humping phenomenon, at the weld root, has not been thoroughly investigated. Therefore, experiments have been performed in this study for the examination of the particular defect. The formation of droplets, towards the rear of this weld pool, was found to be primarily caused by the pumping of melt from the bottom of the keyhole and the influence of the gravity drawing melt on a sagging hump.

From the above, it can be concluded that the formation of some types of defects (e.g., pores, lack of penetration, cracks, humping) in a weld is strongly related to the stability and the solidification rate of the keyhole. The premature collapse of the molten pool, mainly due to high speed, can lead to porosity and humps. Moreover, the rate of the way the length-to-width ratio is reduced, the shrinkage, and the local stresses developed in the surface allow the formation of cracks [23]. Modeling can provide a kind of relation between the process parameters and the existence or the susceptibility of a defect to occur. Therefore, the modeling of the process is critical when quality assessment is acquired in today's competitive industrial environment.

\subsection{Image processing techniques}

\subsubsection{Thermal}

This section contains studies, based on results and conclusions obtained from the thermal field, which is monitored during laser welding. IR thermal cameras are one of the sensing technologies utilized in laser welding applications to capture the temperature distribution to the welded component. Thermal cameras are passive sensors that imprint the infrared radiation, 
emitted by all objects with a temperature above absolute zero [24]. Today, the thermal imaging monitoring systems, as it is mentioned in [25], are more and more implemented into industry, due to the fact that they offer many advantages over other techniques used for detection of the weld pool temperature. However, literature investigation, as far as the application of thermal cameras in laser welding is concerned, has indicated a limited number of relevant papers. Speka [26] used an IR thermal camera, aiming to extract the temperature field during the laser welding of polymers. Numerical simulations were also performed in order to be compared with the corresponding distributions of the temperatures, obtained by IR thermography. By corroborating these types of data, "the reference" temperature profile, which can be continuously compared with the online measured IR profile, has been obtained. Thus, according to the authors, an assessment procedure of optimal process parameters and consequently of qualitative welds is possible. Infrared imaging was also used in [27] for the identification of the weld pool width. On the other hand, the authors in [28] have described an online process monitoring system for quality assurance, aiming to maintain the required penetration depth, which in conduction welding is more sensitive to changes in heat sinking. The implementation of an empirical rule suggests that the maximum penetration in conduction welding is obtained when the surface temperature is just below the boiling point. Therefore, the aim of the control system was that the temperature maintains at this level. To achieve this, a complementary metal oxide semiconductor standard color camera, providing real-time temperature measurement of the welding area, has been used. In addition, Bradin [29] presented a closed-loop control system, which ensured full penetration in welding by controlling the focus position and laser power. The degree of penetration was analyzed by the keyhole image intensity profile, in the same way as it was presented in the previous paper. Finally, the authors examined the performance and the limits of the system when it was applied to a realistic complex aerospace component.

The lack of research studies, as it is observed from the above, can be explained by the fact that IR camera modules usually, due to their dependence on material emissivity, cannot adequately inspect the weld's characteristics and defects that demand additional elaboration of the data in order to match the temperature profile with quality measures. Furthermore, several other disadvantages, such as high cost, low resolution, and low sampling speed, have restricted its wide application to industrial manufacturing [30]. However, the study in [31] has presented a logarithmic complementary metal oxide semiconductor (CMOS) imager for emissivity-compensated thermography, which had thermally stable and optimized inorganic multi-layer integrated filters and a pixel cell, containing a subthreshold load transistor with an optimized device layout. This device provided a rate of $40 \mathrm{fps}$, a measuring temperature range of 600 to $3000^{\circ} \mathrm{C}$, and a temperature resolution of $5^{\circ} \mathrm{C}$. In addition, the authors in [32] developed a new sensor, which combined the ratio pyrometry with $2 \mathrm{D}$-resolved measurement and was compared with the existing temperature sensors in the context of laser processing. The advantages of independence of emissivity and the attenuation of the thermal radiation, together with $2 \mathrm{D}$ temperature information, have been demonstrated on laser cladding. As outcome, the authors mentioned that the temperature distribution to the parts' surfaces becomes available quantitatively and with high precision. Besides the relevant approaches to overcoming the problem of the material's emissivity, normally, the IR modules are combined with vision cameras and/or other optical sensors, targeting at acquiring more information about the melt pool's condition.

\subsubsection{Vision}

Nowadays, the use of vision systems as the monitoring technology of the molten pool is suggested to be one of the most intuitive methods.

\section{Approaches observing melt pool and keyhole characteris-} tics In the technology of laser welding monitoring, using a camera is also being actively developed and there are ongoing efforts to monitor and control the welding processes [33]. In this regard, Huang and Kovacevic [34] have proposed a laserbased vision system for weld quality inspection. The vision sensor was designed based on the principle of laser triangulation and provided information, regarding the geometrical features of the weld. Through the visual analysis of the weld's acquired 3D profiles, the positions and sizes of the weld defects were accurately identified. Another quality assessment approach was presented in [35]. The authors used a calibrated coupled charged device (CCD) sensor and structured light to extract the surface information, as depth of pool, from the captured images. The image was then processed based on the ray-tracing technique for the calculation of the depth of the weld pool surface by using the position of the laser and its fan angle, along with the intrinsic parameters and extrinsic parameters of the CCD sensor. Finally, it was proven through experiments that the method could automatically measure and monitor the weld pool surface within an acceptable error range. Zhang and Cao [36] also developed a vision system with an auxiliary laser light source in order to acquire the images of molten pool for quality assessment. The novelty of the paper and the difference from the previous studies are noticed in the fact that the authors have analyzed the characteristics of the casting shadow of molten pool instead of having analyzed the characteristics of the molten pool itself. The area, the maximal distance among the shadow and keyhole, the maximal width, and the tilt of the shadow were selected as the characteristics for evaluation. The results indicated that the 
welding quality could be online, detected through the observation of these characteristics.

One step further, the authors in [37] proposed a camerabased closed-loop control system by using the image processing algorithm for the identification of a full-penetration hole and concluded that the particular approach was adaptable to partial penetration welding processes. The control system was able to reach and maintain the regime of partial penetration, even under changing welding conditions, while the variation of the cross section (standard deviation over mean value) in all experiments was lower than $10 \%$. In a different approach, the paper in [33] describes a coaxial monitoring system, which integrated an image camera, illumination, and filters. The particular system was applied to a remote laser welding application (Fig. 4). The areas of the keyhole and the full-penetration hole were calculated by image processing, and their behaviors were investigated under various welding conditions. The keyhole was monitored by using various band-pass filters and a coaxial illumination laser. Adequate filters were suggested for steel and $\mathrm{Al}$ alloy welding. The outcome of this study proved the fact that it is possible to monitor and control welding quality measures, such as penetration through the implementation of a coaxial camera system, even for remote laser welding via scanner. Finally, an interesting approach is presented by Tenner in $[38,39]$ where two high-speed cameras are used in order to measure the velocity and the fluid flow inside the keyhole. As a result, the authors were in a position to show the effect of the fluid dynamics inside the keyhole to the laser power, the feed rate, and the gap between two zinccoated steel sheets.

Approaches observing plume and spatters Another interesting approach was investigated in [40]. Authors claimed and finally proved that the plume and spatter have a close relationship with the welding stability. A high-speed camera was used in order to capture the instantaneous images of plume and spatters during laser welding. Characteristic parameters, such as the area and number of spatters, the average grayscale of a spatter image, the entropy of a spatter grayscale image, the coordinate ratio of the plume centroid and the welding point, and the polar coordinates of the plume centroid, have been defined and extracted. After the dimensionality reduction that was followed, the K-nearest neighbor method was also used for the classification of the plume and spatter images into two categories, namely, those of good and poor welding quality. Another work focused on the experimental investigation of the plasma plume with the use of two high-speed cameras [41]. They aimed through different image processing steps to correlate plasma plume with keyhole evolution. The extracted relation was used to explain the effect of changing laser power and feed rate on the keyhole geometry. In addition, authors in [42] have compared the spatters produced during laser welding by a bifocal optic setup with those produced

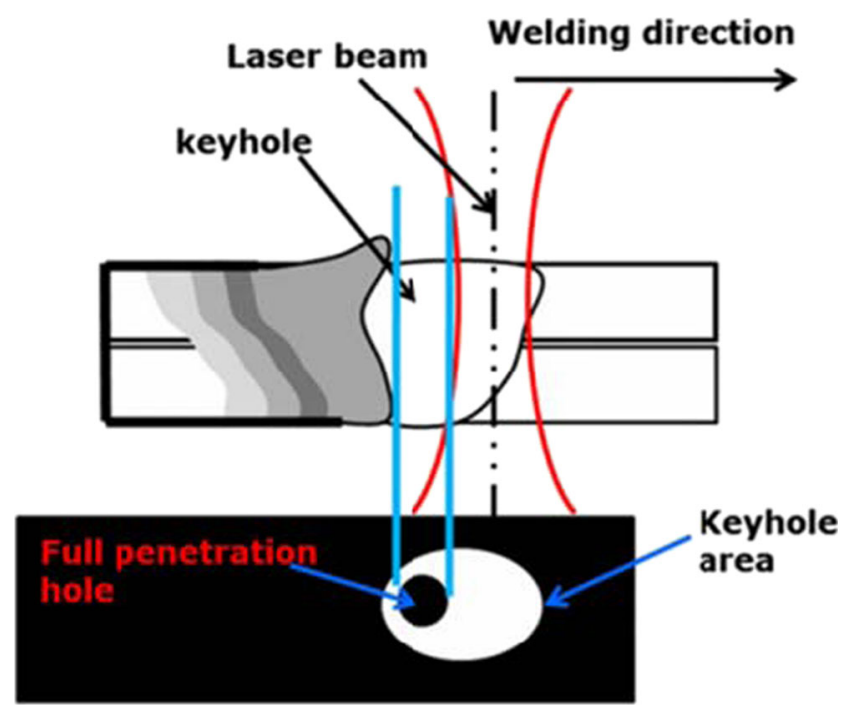

Fig. 4 Definition of the keyhole parameters [33]

from a conventional one and concluded that the bifocal optic has an influence on the keyhole dynamics, observed from the spatter size and number. Experiments were performed with the use of a high-speed vision camera and indicated that the bifocal optic produced a smaller quantity of spatters, in a bigger size, due to the high-intensity areas in the lower keyhole sections. The occurrence of big spatters was a disadvantage as they solidified and remained on the material's surface. In the observed parameter field, the bifocal welding had no positive effect on the spatter characteristics, when the same processing parameters as those in the standard process were used.

Generally, it can be observed that the combination of visual sensing technology and the image processing have been widely investigated by providing new research opportunities and concrete solutions in the process' laser welding detection and quality assessment. However, there is a lack of temperature feedback which excludes valuable information for the physical phenomena that occur during laser welding. Furthermore, the accuracy of the keyhole geometrical parameters captured by a visual sensor is highly dependent on the implemented image processing technique [36]. Thus, the capabilities of such systems for adequate quality inspection are limited. In this regard, combined vision and thermal sensing can offer a flexible monitoring system and lead to the identification and evaluation of more magnitudes that concern the weld's quality.

\subsubsection{Combined vision and thermal image processing techniques}

As it is observed from the previous section, visual sensing can significantly contribute to the quality assessment procedure of laser welding, through the provision of higher spatial measurement and the accurate location and identification of weld defects. However, vision cameras (CCD and CMOS) are not 
suitable for detecting mid- and long-wave infrared radiation, and for this reason, specific infrared cameras are required [43]. This argument is also mentioned by Voelkel and Mazumder [44], who suggested that the passive illumination was entirely insufficient for capturing details of the melt pool by providing very dark figures of the melt pool. The diffuse light alone revealed more details on the area of the melt pool, but the best results were received from the combination of the focused and diffused laser light. In this regard, combining different thermal and vision methods for the inspection of quality in laser welding applications would incorporate the advantages of each method and would enable the engineers to monitor different weld defects and magnitudes.

A novel mechatronic approach of using infrared thermography, combined with image processing for the quality control of a laser sealing process for food containers, has been introduced in [45]. The infrared camera was found to be capable of detecting the localized heat pattern, any contamination between the film and the container, and the materials' cooling behavior after welding. On the other hand, the visual system provided a quality assurance system for the integrity of the sealed products. Finally, as future work, the authors have suggested the development of an experimental apparatus into an industrial system for the sealing of plastic containers (Fig. 5).

In contrast with the above study, the one described in [46] focused on the control of temporal strain development and solidification cracking in laser welding of aluminum alloys. High-speed observation of visible and infrared radiation was performed to measure the molten pool geometry, velocity of the solid-liquid interface, and temperature profile, during laser spot welding. The solidification rate along with the interface velocities, during the cooling procedure of the welding, was examined in order for a crack-free and full-penetration beadon-plate seam welding to be achieved with overlapping spot welds. In addition, the development of an on-axis camerabased online sensor system, for laser welding diagnostics, has been investigated in [47]. The researchers added a camera that monitored the welding zone in the near infrared range (NIR) spectral range between 1200 and $1700 \mathrm{~nm}$. With this add-on detector, additional information beyond the VIS range could be obtained. Features from the images were extracted and evaluated to characterize the welding process. Among the others, it was concluded that the full-penetration hole was clearly observable and the weld pool dimensions were successfully correlated with those of the penetration. The quality assessment of laser welding with the use of camera-based monitoring systems, both in NIR and VIS spectral range, is also the subject of the paper in [48]. The classification of the welds was performed on the basis of various welding faults. For instance, the weld pool geometry was correlated to full penetration, holes and spatters could be identified without additional illumination, and the thermal trace of the weld seam could detect missing fusion.

Combined camera-based solutions (vision and thermal) depict a costly monitoring technology, and therefore, their use in laser welding has not been widely adopted. The findings from
Fig. 5 a Schematic diagram of the sealing monitoring system. $\mathbf{b}$ Left: good weld (after $5 \mathrm{~s}$ ), right: bad weld (after $5 \mathrm{~s}$ ) [45]

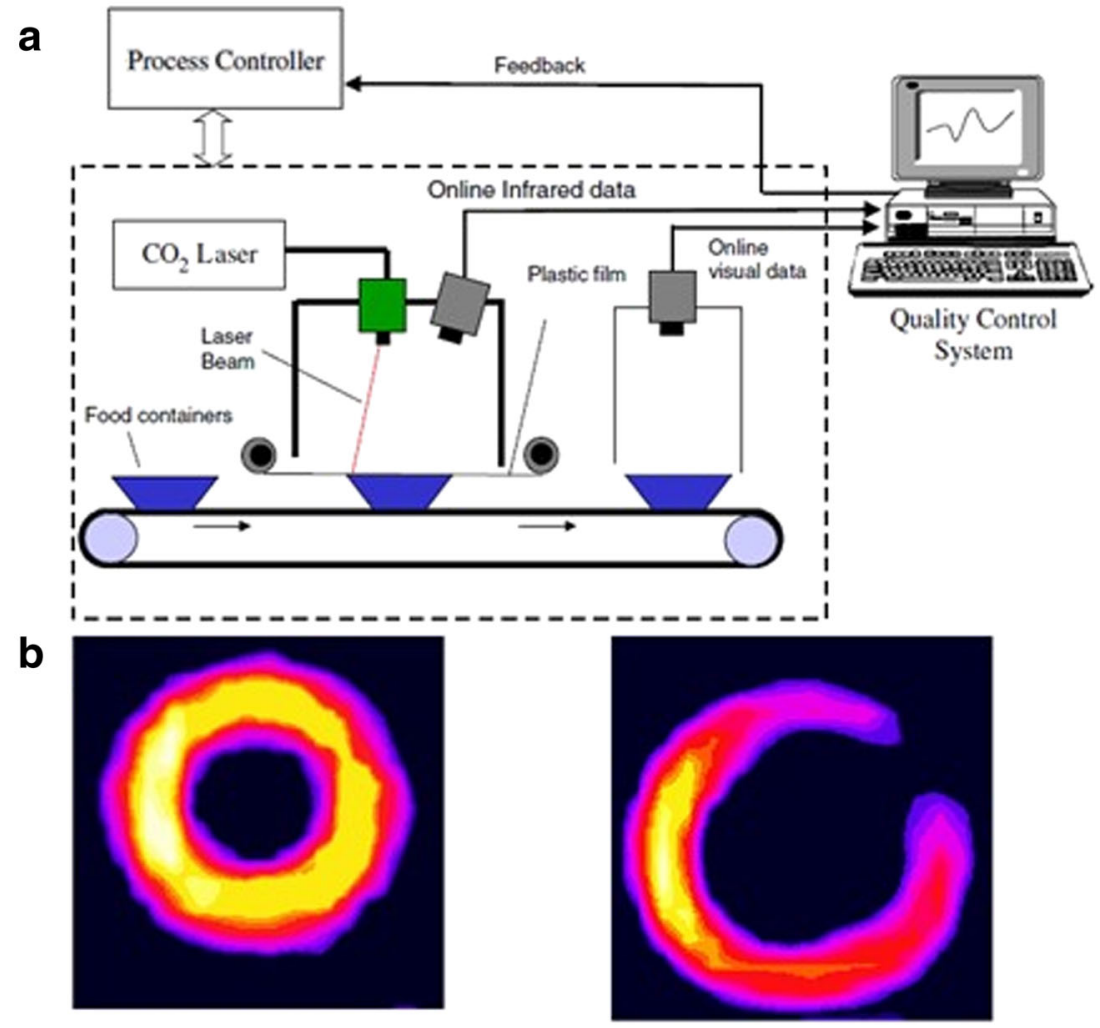


the literature review have indicated a lack in published papers, but strengthened the opinion that several combined camerabased and other sensor-based (photodiodes, spectrometers, pyrometers) technologies have been developed targeting at monitoring more and different quality measures, during laser welding. The latter is proven by the extensive review presented in another section of this paper.

\subsection{Acoustic emission techniques}

Acoustic emissions contain considerable information on the laser welding process and can indicate certain aspects of the weld quality. It has also been claimed that acoustic sensing techniques could be applied to processes that involve melting, vaporization, plasma generation, and keyhole formation [43]. Moreover, acoustic emissions can provide useful data regarding the rapid phase change in the material as well as the formation and propagation of cracks [49]. However, only few studies that evaluate the quality have been published. Despite the flexibility that the non-contacting acoustical sensors provide in applications, where the use of contacting sensors is not feasible, the existence of noise from the surroundings and the slower transmission of the signal inside the material make the sound detectors not useful in adaptive control and in-process quality assessment approaches. Therefore, the studies found in literature focus on the improvement of identification accuracy and the development of intelligent algorithms for the correlation of signals with weld geometry and defects. The last argument has also been demonstrated by the authors in [36].

By implementing wavelet analysis, the authors in [49] noticed a significant difference between the acoustic emission (AE) signal from the desired deep-penetration weld and that acquired when there were problems with misalignment and excessive gap. The intensity of low frequencies $(<781 \mathrm{~Hz})$ was reduced when welding defects occurred. Based on the detailed information, obtained from AE signals, a signal intensity moving average curve was defined. The curve was used in order to identify defects and recognize transitions of the welding stages. Li in [50] has compared two types of ultrasonic acoustic emissions in order to extract the relation between the acoustic signals and the thermal phenomena such as melting, vaporization, and plasma generation, taking place during laser processing. The author has concluded that the "acoustic mirror" signal is mainly generated by the melt pool-modulated laser beam backreflection (between 100 and $600 \mathrm{kHz}$ ) rather than by the laser cavity modulation (5$25 \mathrm{MHz}$ ). The signal was strongest on the beam guide mirror being closest to the work-piece. When a keyhole was generated, the acoustic mirror signal became weaker, while the "acoustic nozzle" signal became stronger. At the end, the author noted that the acoustic sensing techniques, as described in the paper, could be applied to in-process monitoring and control systems for laser processes, evaluating the quality of the inspected welds. One step further, the authors in [51] selected acoustic emissions for the feedback signal of an inprocess monitoring scheme for a pulsed Nd:YAG laser spot welding (LSW). Acoustic emission data were sampled and analyzed for varying process conditions, such as laser power and pulse duration. Afterwards, through an empirical model, it was shown that acoustic emission signals had clear correlations with process parameters and represented welding process characteristics, including welding types and possible crack initiation mechanisms during LSW. Finally, an artificial neural network was used to predict the weldability of stainless steel online. Another study that related weld quality with acoustic emissions was described in [52]. The authors anticipated that the weld quality data obtained from wavelet analysis could be fed on an online industrial application in order to control critical weld parameters or alert the operator of a problem. Internal weld defects and deviations from the desired surface profile could then be corrected before the production of defective parts.

\subsection{Optical signal techniques}

Based on the number of written articles, optical sensing techniques are used most frequently for the monitoring of laser processing. The optical sensors are classified into the literature differently, depending on the writer [36]. A usual classification that is made by several authors is a division into spatially resolved (vision system, e.g., CCD and CMOS cameras), spatially integrated (photodiodes), or spectrally resolved (spectrometers) techniques [53]. In this section, quality assessment methods, based on the particular optical sensors, have been included. However, according to the classification presented in this study, the vision systems have been introduced and developed above, as a part of the image processing techniques. Pyrometers are also incorporated into this section despite the fact that in several papers they are grouped into the thermal methods category [54]. Finally, reference should be made about the research outcome on the in situ interferometric based keyhole depth and the topography monitoring and control of laser machining and specially in laser welding. Authors in [55] combined the inline coherent imaging (ICI) system with a beam directing system at the camera port of a commercial, fixed-optic laser head and were able to dynamically steer the ICI system's beam across the sample surface, at millisecond timescales. By sampling data from multiple points in and around the phase change region, they were able to implement autofocus and continuously correct any motion error and distortion in the measured keyhole depth. In addition, transverse measurement sweeps of the leading region, in common joint configurations, enabled seam tracking for the closed-loop correction of imperfect part geometry. The combined realization of these capabilities makes the ICI system a more robust and 
versatile weld process control and quality control solution. On the other hand, the authors in [56] combined a laser-induced breakdown spectroscopy (LIBS) optical setup with the interferometer by providing in situ accurate depth measurements and detailed crater profile mapping. The elemental information extracted from the spectroscopy spectrum could be directly correlated with the depth and topography measurement, having resulted in the accurate mapping of the elemental profile, along the normal to the sample surface. Details on the optical setup, along with several examples on the elemental depth profile analysis, were presented, and issues regarding the speed of depth monitoring and the limitations of the setup were also discussed.

Photodiode Photodiode sensors are widely used in industry because of their simple structure and low cost. The optical radiation signals that can be detected by photodiodes, during laser welding, can be within UV (200-400 nm), VIS (400$700 \mathrm{~nm})$, NIR (700-1100 nm), and IR (1100-1700 nm) range. The corresponding signals are analyzed in order to provide information about the welding status and the detection of defects. According to the literature research conducted, it was concluded that photodiodes are normally used to detect vapor plume or plasma, reflecting laser energy and thermal radiation. In this regard, the measurement of the plasma and spatter, during laser welding with UV and IR photodiodes, has concerned authors in [57]. Five welding factors (optimal heat input, slightly slow heat input, low heat input, partial joining, due to gap mismatch, and nozzle deviation) that influence weld quality were examined, and a correlation between the input signal and these factors was performed through experiments. A system was also developed to perform real-time evaluations of the weld quality with the use of fuzzy pattern recognition with the measured signals. The UV and IR signals received from photodiodes were also used for weld quality assessment in [58, 59]. The novelty in [58] is the implementation of such a sensing technology and quality inspection in underwater laser welding. The authors claimed that the shielding condition of the local dry cavity was a significant factor for adequate penetration. On the other side, in [59], the experimental work has provided a better understanding and accurate evaluation of the laser welding through the quantification and analysis of the feature, extracted from different optic sensors (UV, IR, VIS). Indicatively, the variation tendency of the visible light emission and the metallic plasma size on the top is consistent, while the laser reflection intensity is sensitive not only to the laser power but also to the keyhole size. Moreover, due to the pressure released from the bottom of the keyhole, the visible light emission and the laser reflection were reduced when full penetration appeared during the welding process. However, the authors in [16] presented a method, which is mainly based on the visible spectrum range. This radiation is transformed into electrical signals, whose properties are studied both in time and frequency domains. The characterization of those properties allows the seams to be classified according to their quality. Results have shown that $97.1 \%$ of the defects were detected. According to the authors, although these results were satisfactory from a technical point of view, they did not achieve the objective of having all the defects detected. Furthermore, the study performed in [60] used also the photodiode reading in a visible and infrared range succeeding to identify not only lack of penetration but also craters, spatters, blowholes, underfill, lack of fusion, or pores. From the findings, a more general theoretical description of the links, between the welding process, the defect mechanism, and the generated signal, was also described. On the other hand, the studies in [61] and [62] described a monitoring system developed only on the basis of infrared signals. The primary infrared signal collected by the weld monitor was linearly related to the penetration depth in partial penetration welds. Full penetration was signified by a considerable drop in the direct current (DC) level of the signal, as well as an increase in the AC component. The weld monitor technique, according to the authors, was very sensitive to penetration depth, especially the detection of full penetration. However, part misalignment and oil contamination lead to significant variations in the weld monitor output. Finally, the authors in [63] described the development of a monitoring system that used photodetectors to measure the radiation signals from the melt pool. By changing the focus of the laser beam, along the $\mathrm{z}$-direction, the penetration depth of the welding material was measured. The latter showed that the penetration depth was dependent on the frequency fluctuations of the plume signals, which can be used in welding quality control.

Spectrometer Spectral analysis has been widely used in laser welding for the detection of the plasma plume. The monitoring of the plasma indicates the formation of undercut in the welds. The usual setup of this sensing inspection technique is illustrated in Fig. 6, and as it can be extracted from the schematic, the optical emission is collected by a collimator and transferred by an optical fiber to the spectrometer, where the signal is analyzed [64]. The research conducted in literature has led to the conclusion that recently the use of the particular sensor has met a wide acceptance in industrial applications $[65,66]$, mainly due to its low cost and compact size. The approach of the monitoring technique, adopted in [64], was based on the correlation analysis of plasma plume optical spectra, generated during the process and recorded through a spectrometer. Experiments were conducted in order to identify the relationship between optical signals and weld quality. The quality of the welds was finally evaluated through an online detection of common defects, such as lack of penetration with an excellent spatial resolution. Rizzi and his colleagues [67] developed a regression model, which allowed the study of the 
Fig. 6 Monitoring system with spectrometer [64] focusing head

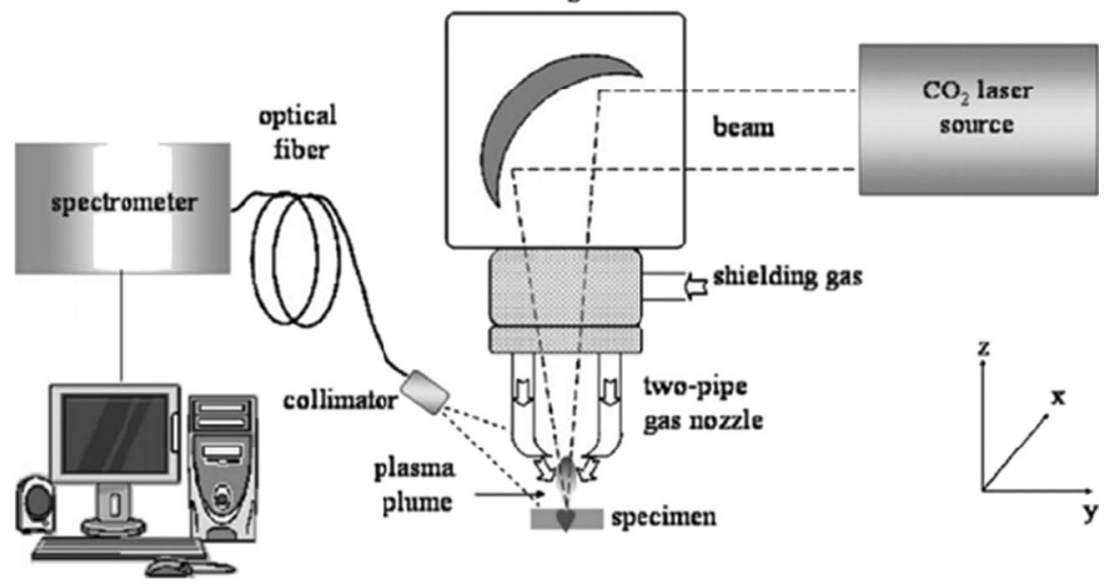

laser beam's influence on response parameters, namely, plasma plume temperature, penetration depth, and melted area. As it is noted from the authors, their study is a starting point for the development of a closed-loop control system. A spectrometer was also used in [68] for the collection of the optical emission of the welding area. The sensor data were used to calculate the electron temperature and subsequently to determine the weld quality of overlap welds. The particular inprocess monitoring method was implemented into a proportional-integral (PI) controller, which adjusted the laser power, aiming at a constant penetration depth. The correlation between electron plasma temperature and weld penetration was investigated by the researchers in [69]. The frequent implementation of spectroscopes is also proven in [70]. In that paper, a novel spectroscopic closed-loop control system, capable of stabilizing the penetration depth, during laser welding processes by using the laser power as the control variable was described. The plasma electron temperature was monitored, and through a quantitative relationship between the penetration depth and the plasma temperature, extracted experimentally, the system reduced the rejected components due to incomplete or excessive weld penetrations. The phenomena related to the optical emission of the laser-induced plume have also been widely investigated, and various innovative spectroscopic systems such as the one presented have been developed in [71].

Finally, Mrna [65] presented a different approach to the optimization and feedback control of the laser welding process, based on spectroscopy. A frequency analysis of the light, emitted during the process and the adaptive shaping of the laser beam, was achieved by an optical element. Correlation among the focal properties of the laser beam, the weld depth, and the frequency characteristics were experimentally extracted. The functionality of the method is demonstrated for a variety of welding parameter settings that are frequently used in industrial practice.
Pyrometer Pyrometers are another category of the sensing technology, adopted in laser welding for quality assessment. The thermal radiation intensity reflects changes in temperature and can be detected with the use of a pyrometer sensor [36]. The existence of defects or the penetration and width values can be obtained from the variations of the temperature field. Smurov [72] with his study strengthened the above arguments and claimed that pyrometers can be used for real-time temperature monitoring and online quality control. Moreover, the authors mentioned that the pyrometers are preferred due to their low cost, the simplicity in utilization, the high efficiency in sampling, and the special software, developed for this purpose. Furthermore, the studies presented in [73, 74] and [75] developed a monitoring system, based on pyrometers, and attempted to optimize a laser welding process. The true temperature, heating/cooling rates, and solidification duration were determined, and the acceptable variation in brightness temperature was found. Then, the authors proceeded with the correlation between sensing feedback and weld defects. Finally, it was concluded that the performance of the sensors was adequate for the control of the process.

\subsection{Fused sensing techniques}

Besides the combined image processing techniques, several authors have focused on multi-sensor approaches for the exclusion of drawbacks of single-sensor solutions and the identification of more kinds of weld defects. In extension to this, they strongly believe that the multi-sensor approach can be the answer to accurate and effective quality assessment. In several attempts, infrared and ultraviolet sensing was combined with acoustic detectors. The use of photodiode sensors is considered being more accurate for penetration and keyhole defects. Controversially, acoustic detectors are rather sensitive to capturing changes in plume. Indicatively, as it is described in [76], a multi-sensor monitoring system was integrated into a laser 
welding machine. The classification of the welds into two states (adequate penetration or inadequate penetration) was conducted on the basis of features, extracted from infrared visual and acoustic sensors. Further experiments indicated that the system was feasible for monitoring laser welding processes in real time and the evaluation of the weld's quality could be performed from the input, received by the particular multisensor inspection approach. The detection and analysis of optical, acoustic, and plasma charge emissions of quality monitoring was the subject of the research performed in [77]. It was observed that the transition from full to partial penetration could be detected from the optical sensor. The airborne acoustic signal was found to be loudest at moderate full-penetration conditions and was observed to be decreasing when weld penetration was transitioned from full to partial. The studies in $[78,79]$ also deal with the detection of quality measures (penetration) in laser welding, based on the multi-sensor inspection approach (photodiode-microphone [78] and spectrometer-microphone [79]). However, two main limitations were identified by the authors of the above papers. The first one concerned the conclusion that an accurate distinction of different weld defects was not achieved due to the fact that the weld defects showed similar signal features. Their second remark pointed out the weakness of the inspection approaches for the identification of defects with little feature variation. The particular signals were covered with noise of greater oscillation amplitude.

Another multi-sensor configuration that is often met in literature has to do with the integration of visual sensing and photodiode sensing. The advantages of high sampling speed and great information capacity provide valuable feature information during the welding status detection. You et al. published two interesting studies in which a multi-sensing system of laser welding was presented $[59,80]$. Two optical signals, visible light and laser reflection, were collected by photodiode sensors. With the aid of image processing, three geometrical features, including keyhole size, metallic vapor at the top, and metallic vapor at the bottom, were obtained by the visual sensor. Furthermore, according to the authors, a systematic analysis could be conducted on welding stability through the comparison of the feature signals obtained. It was also mentioned that even for online adaptive control, the multi-sensing system reveals more detailed information about the recognition of the welding process. Figure 7 depicts the experimental setup of a multi-optical sensing system.

In addition, Norman and his research team also presented a fused sensing approach and measured, in an optically filtered spectral window, the thermal emissions from the melt and vapor as well as the laser beam reflections [81, 82]. The concept proposed in these papers concerned the context among the photodiode signal, the welding defects, and the melt pool, keyhole, and temperature dynamics. Simultaneous laser-illuminated highspeed imaging was compared with photodiode monitoring at three spectral windows for the identification, through simultaneous timing, of any linking dynamics in a qualitative manner. Emission modeling and thermal imaging were considered to be supportive methods. Several cases
Fig. 7 Experimental setup of a multi-sensor monitoring system [59]

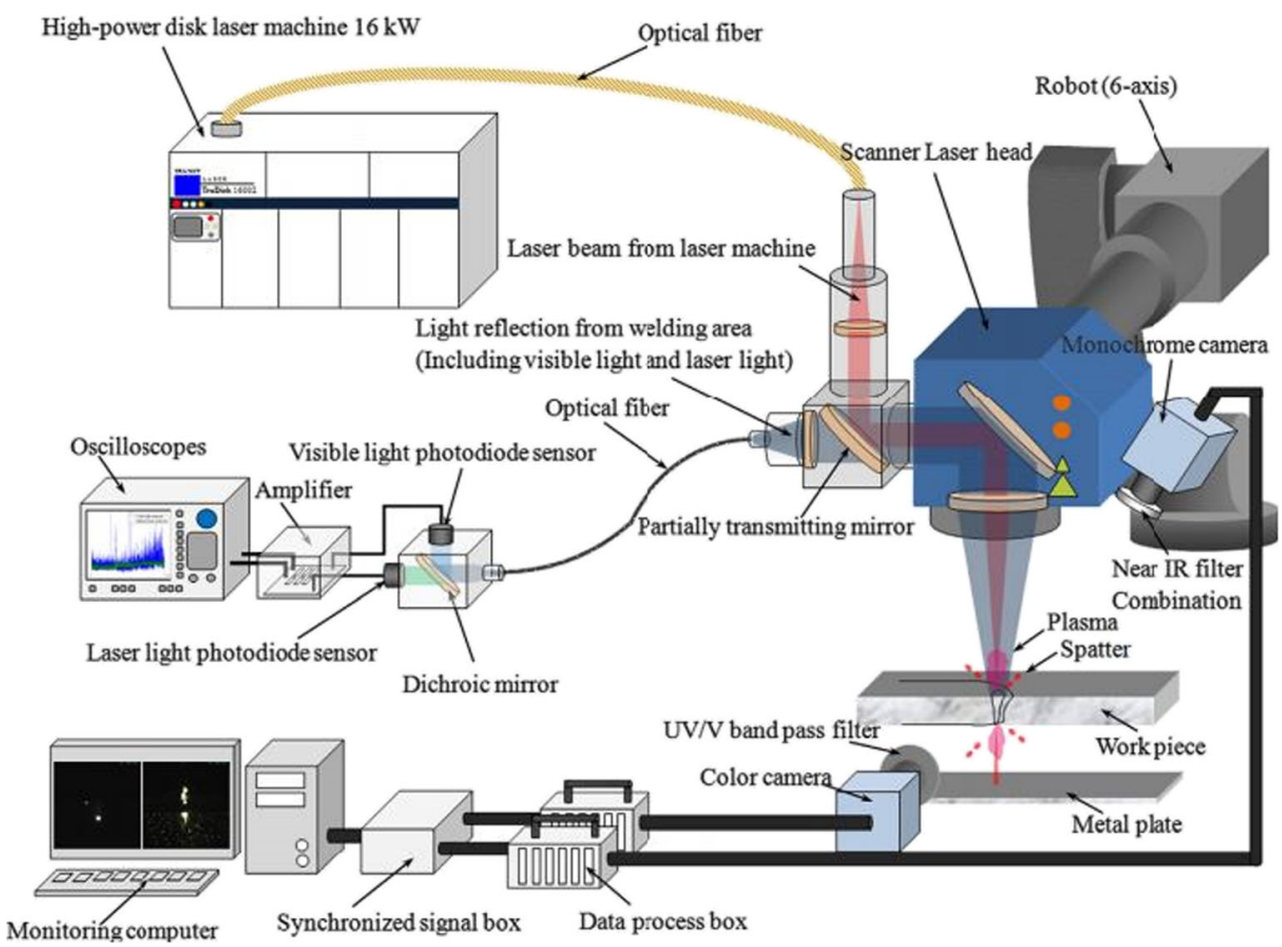


Fig. 8 Correlation of sensing signals with welding status [83]

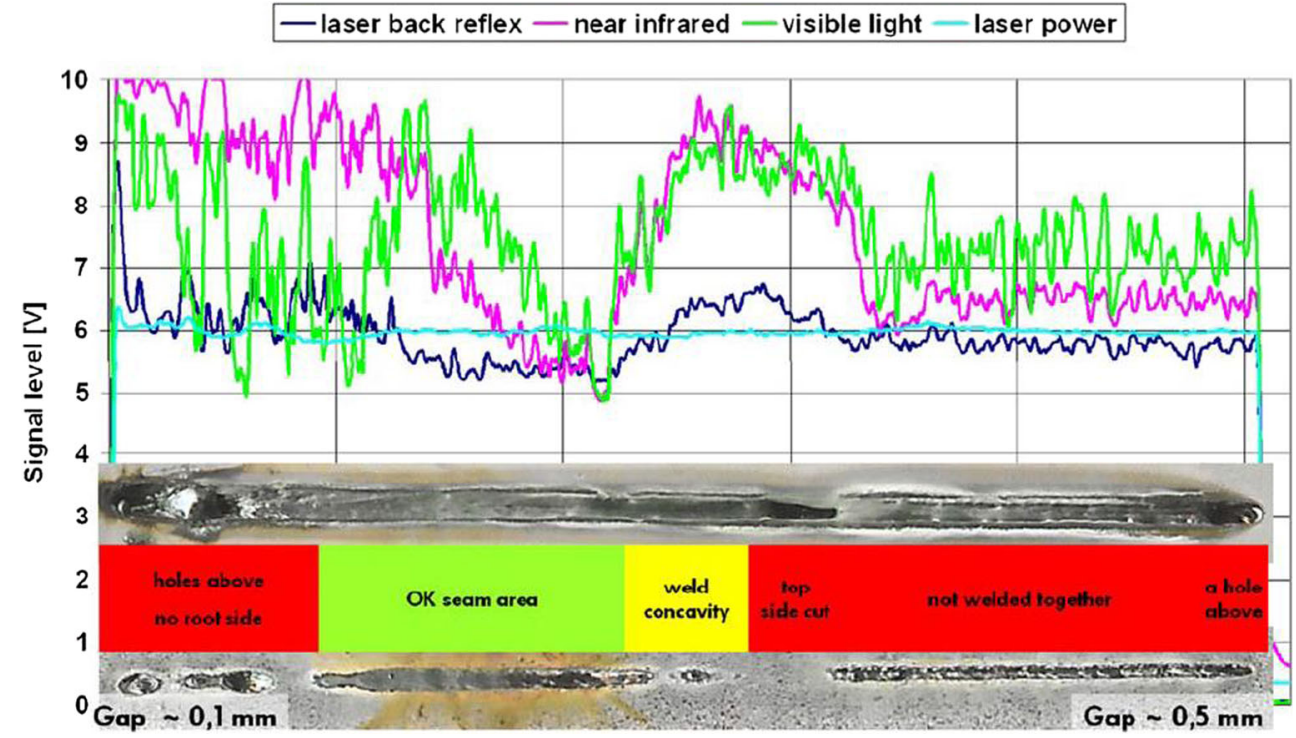

of joints, materials, and defects were also studied for the creation of a theoretical description of the defect-signal correlation.

A complete quality assessment system for laser welding has been developed by Volkswagen and the FhG Institute for Machine Tools and Forming Technology. The particular multi-sensor system, according to [83], can be used for the online detection of various weld defects. Figure 8 depicts the sensing signals and the image received, at the same time conducting quality evaluation of the weld. Additionally, an in situ quality control system which integrates a high-speed NIR thermal CMOS camera and a photodiode coaxial with the laser beam is described in [84]. The particular approach was developed for the selective laser melting process linking the melt pool variations with pores that are present, predicting the quality of the parts. However, the particular quality control system could be also used in laser welding especially when porosity appears during the collapse of melt pool and affects the quality of the welds [85]. Finally, Table 3 below classifies the papers cited in this section according to the monitoring technology implemented and the detected process phenomena and defects.

\subsection{X-ray techniques}

The inline $\mathrm{x}$-ray imaging, during the laser welding itself, is a well-established method for the examination of the keyhole behavior with side view through the material. As it is mentioned in [85], lately, the image capturing has become faster and the maximum possible sample width has been increased. In this regard, Vänskä et al. [85] described an in-situ x-ray videography inspection technique, which enabled the recovery of time- and space-resolved information about the keyhole geometry, during the laser welding process. Two different joint types were used, and the experiments performed showed the effects of a welding speed and a focal point position change in the keyhole's geometry values. Alternatively, in [38], the effects of the laser power, power density, and welding speed on the formation of welds were investigated and their welding phenomena were explained via high-speed cameras and the $\mathrm{x}$-ray transmission real-time imaging system. The experimentation performed has revealed that the laser power density exerted a remarkable effect on increasing the weld penetration, indicating that in a wide range of the welding speed, between 4.5 and $10 \mathrm{~m} / \mathrm{min}$, no porosity under filling or humping was observed. Furthermore, the study in [86] fully exploits the potential of x-ray imaging techniques being used online as well. A real-time automatic inspection algorithm for weld defects in x-ray images was developed, with the use of optimized image smoothing and image information fusion, based on heuristic search techniques. As a result, the algorithm could detect different kinds of welding defects, such as slag inclusion, blow hole, incomplete penetration, lack of fusion, and undercut. Experiments have indicated that the system was efficient and reliable and could be used for industrial purposes. Katayama and his research team have focused on the $\mathrm{x}$-ray radiography with emphasis on the analysis of pore formation and melt flow [87]. In addition, the same authors in $\mathrm{xx}$ described the real-time observation of keyhole and plume behaviors in the pulsed- and continuous-wave laser welding by high-speed optical and x-ray transmission methods, the cavity formation process, and its suppression measures. Finally, Naito et al. [88] showed the YAG laser welding of stainless steel, type 304 with $\mathrm{x}$-ray visualized keyhole, during the process. The focus area of their study was to track the melt flow during the YAG laser and TIG-YAG hybrid welding. The 


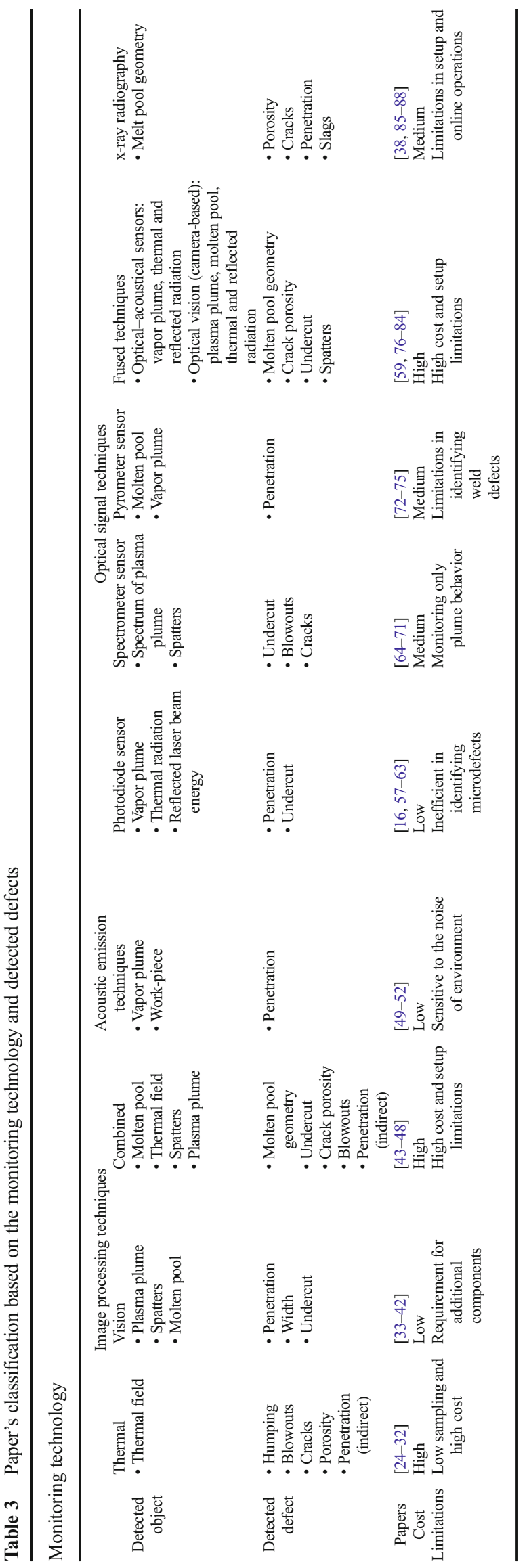

melt flow was visible, but the keyhole geometry was not fully visible.

\section{Modeling approaches to laser welding for quality measure estimation}

In this section, the paper focuses on several modeling approaches developed so far, aiming to correlate the process parameters with the weld quality measures, such as the melt pool geometry and the afore described weld defects (porosity, cracking, and humping). The particular section is structured on the basis of two main modeling categories. Analytical and empirical types of modeling are thoroughly investigated into and described below. The numerically solved analytical models are included in the corresponding subsection.

\subsection{Analytical modeling}

Penetration depth is one of the main weld characteristics concerning the researchers in modeling laser welding, and several papers have been published with reference to its relation with the thermal field. Chryssolouris and Yablon [89] presented a method that estimated the depth in laser machining processes, based on temperature measurements. An analytical model, relating the temperature to the groove depth, was used for predicting the depth, given a temperature measurement and its location. The model, derived by solving the 2D steady heat conduction equation, modified to take into account the effects of the relative motion between the beam and the work-piece. One step further, Lankalapalli [90] proposed, as in [89], an analytical model which estimated the penetration depth, based on a 2D heat conduction model. Moreover, a conical keyhole assumption was considered and the relation between the penetration depth, the incident power, which was assumed to be equal with the absorbed power, and the Peclet number was developed. As it is mentioned by the authors, the Peclet number is a function of the welding speed, the keyhole radius, and the thermal diffusivity. The model was validated by a number of experiments, and its consistency with the theoretical values dictated that the model could be used as a basis for online depth estimation schemes and coaxially orientated camera configurations. On the other hand, Dowden and Kapadia [91] developed and proposed a mathematical model, whose beam had a uniform intensity. An analysis in terms of geometrical optics and a parallel beam verified the empirical observation that the radius at the bottom of the keyhole, in a work-piece of maximum thickness for the occurrence of complete penetration, is one third of the radius at the top. Geometrical optics applied to the same criterion, in a conical keyhole, gave new estimations for the thickest workpiece in which complete penetration could occur. Finally, the conclusions provided by the theory were compared with 
experimental results and were found to be in good agreement. Instead, research performed in [92] described the development of a model for the prediction of the penetration depth which was introduced as the ratio of the total absorbed power to the average line source power. The average power was calculated from the power at the bottom and the power at the surface. In addition, the model predicted the top and bottom weld width and the results indicated a close agreement with the experiments performed. The model also enables the analysis of the weld profile's dependence on the process parameters. Volpp and Vollersten [93] claimed that in order for process defects to be avoided, the physical effects in the keyhole have to be better understood. In this regard, they described the keyhole properties for welding aluminum, at different welding parameters, with the help of a semi-analytical model, based on energy and pressure equations and differential equations. The resulting dynamic characteristics of the different keyholes were evaluated with the frequency analysis of optical observations during the welding process. Finally, the dynamic behavior was influenced by the spatial laser intensity distribution, while higher frequencies, at lower amplitudes, were found at a top hat distribution compared to a Gaussian intensity profile. In a more advanced approach, the author in [94] provided a 3D solution of the heat flow in laser beam welding with a constant moving Gaussian heat source. The model was extended to determine the penetration depth, bead width, and cooling rate, which were important for the prediction of metallurgical structures and consequently the weld's quality. The normalized temperature rise and cooling rate, produced by a moving Gaussian beam, were dependent on the ratio of the scanning velocity to the thermal diffusion and on the ratio of the beam spot radius to the absorption depth. Additionally, in laser welding, the maximum possible penetration depth for known laser power, the travel speed, and the beam spot size could be predicted by this model. Finally, the calculated penetration depth for carbon and AISI 316 steels were in good agreement with the experimental results.

A numerical implementation of a 3D finite element model has been developed in [95] aiming to dynamically simulate the laser full-penetration welding process. The authors, based on the model developed in [90], predicted the penetration depth and the weld width from the calculation of the transient temperature profile. The strength of the line source was calculated as a function of the Peclet number and the conductivity with the assumption of a conical profile of the keyhole. Various values of conductivity were examined for different welding speeds, in order for the best agreement between the model and experiments to be obtained. Finally, the results suggested that for different welding speeds, an effective material conductivity should be used for the prediction of the weld cross section and that the weld shape is a strong function of the Peclet number and the material's conductivity. Authors in [96] presented a numerical model, based on the combination of the enthalpy method, and the finite difference techniques were applied to the heat equation that could bypass the manual enforcement of the jump condition, at the phaseseparating surfaces. Minimal application of the "life and death of elements techniques" was required in order for the dynamics of the keyhole to be captured. The work resulted in the creation of a software tool, capable of predicting the keyhole and melt pool characteristics of various materials and process parameters. On the other hand, the authors in [97] developed their models with a commercially available software and based on the finite element method (FEM) validated the simulation results of the weld shape with experimental values of stainless steel welding. Moreover, the authors in [98] also developed an FEM model, aiming to investigate the thermal phenomena and microstructure of Ti6Al4V and 42CrMo laser welding. Based on the model, a temperature field with various laser power values and scanning velocities was calculated to explore the relationship between the process parameters and the interface temperature. As the authors have mentioned, from the numerical simulation and experimental investigation, the calculated temperature history, at measuring points, had a tendency similar to that of the experimental results. Finally, the interface temperature could just reach or be a little higher than the melting point of the lower sheet material $42 \mathrm{CrMo}$ through the adjustment of the process parameters according to the numerical calculation. However, Abderrazak in [99] took also into consideration the Marangoni effect that simulated the flow of melted material inside the melt pool, resulting in a different weld pool shape. The relationship between the penetration depth and the width with the process parameters has been experimentally verified in the last sections of the particular paper (Fig. 9).

Despite the modeling performed on the subject of correlation of the thermal field with the melt pool geometry, several studies have been also published aiming to make a numerical investigation into the susceptibility of a weld defect to appear, depending on the simulated temperature field and the process parameters [100, 101]. Indicatively, Zhao and DebRoy in [102] developed a numerical model in order to predict the keyhole geometry and the temperature profile. The model can be used in order to prevent the macro-porosity formation, during the laser welding of aluminum alloys. The authors, based on the observation that the weld metal contained large pores when the welding mode changed from conduction to a keyhole mode or vice versa, were able through their model to predict the macro-porosity formation when the welding mode occurred due to alteration in the process parameters.

\subsubsection{Empirical modeling}

Empirical modeling has been extensively used in laser welding in order for the optimum process parameters for high quality to be identified through the conduction of a series of 

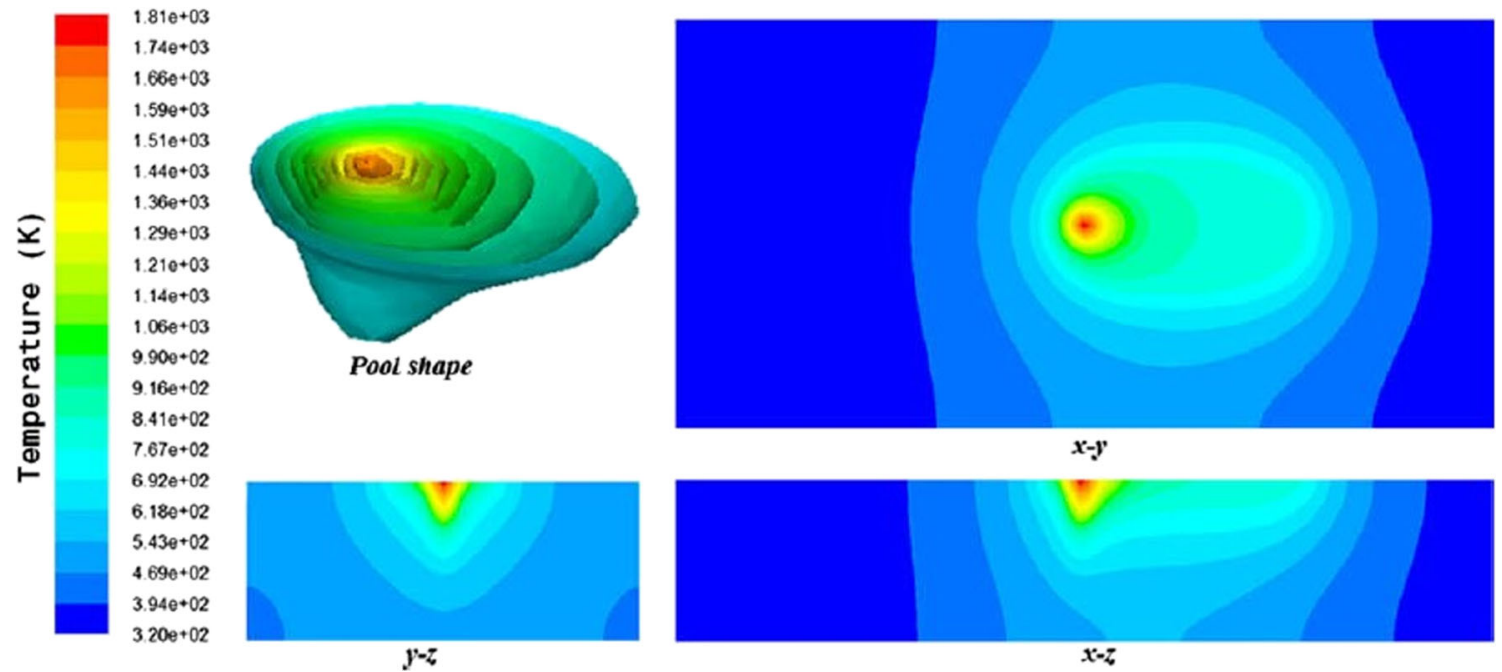

Fig. 9 Calculated temperature field in different sections with Marangoni effect (1000 W, $5 \mathrm{~m} / \mathrm{min})$ [100]

experiments. Recent advances in the development of empirical modeling algorithms (such as those of machine learning) have helped in the extensive implementation of the method in a wide range of manufacturing processes, especially in those whose quality in products is highly dependent on several process parameters. Authors in [103] used the Taguchi method in combination with gray relational analysis in order to optimize process parameters with respect to weld strength and width. Furthermore, in [104], the researchers optimized the $\mathrm{CO}_{2}$ buttwelding process in the ranges of the investigated parameters (power, welding speed, focused position) using the Taguchi approach and artificial neural networks. In a similar approach [105], some of the previous papers' authors have extended their work by implementing the analysis of variance (ANOVA) method to investigate which welding process parameters significantly affect quality characteristics. By slightly altering the quality metrics, the results indicated that for the welding pool area the main effect was the welding speed while for the weld pool width there was a linear relationship among the main effects of the three investigated parameters. Finally, for the welded pool width, in the middle of the work-piece, the method indicated laser power as the most affecting parameter. The same issue with similar approaches, but with different process parameters for investigation, quality metrics, and specimen's material, has also been addressed in [106-109]. Furthermore, the authors in [110] have used backpropagation and learning vector quantization neural networks for the prediction of the laser welding parameters of butt joints. Work-piece thickness and welding gap were used as inputs, while the output parameters "responses" were optimal focus position, acceptable welding parameters of laser power, welding speed, and weld quality, including weld width, undercut, and distortion. A fuzzy system for real-time inspection of specific anomalies (such as anomalies in the current, voltage, or speed of the arc, contamination with other materials, holes) and the position of defects were also developed in [111]. In an extensive experimental comparison, the fuzzy system outperforms a former version of the detection algorithm, based on a statistical approach. The system was mostly applied to the arc welding process, but the authors believed that since the detecting emissions (UV, IR, and VIS) were also generated in laser welding, the implementation of such a system would be feasible in the particular process too. An interesting study was also described in [112]. The researchers underlining the difficulty of taking in-process measurements of the penetration depth and the inclination angle, even if the keyhole size can be detected by using a visual monitoring system, trained a static neural network in order to establish a correlation between the welding parameters and the keyhole geometry. The dynamic state observer was also trained on the basis of the transient welding conditions, predicted by a numerical model, and then were used for the estimation of the time-varying keyhole geometry. Finally, a coaxial monitoring system was used in order to observe the keyhole shape in real time, provide input to the neural network, and indicate potential welding porosities (Fig. 10).

The researchers in analyzing acoustic signals during the keyhole and conduction laser welding, in [113], concluded that the intensity of low-frequency $(<781 \mathrm{~Hz})$ components, of the sound signals, decreased dramatically when welding defects occurred and the shape of the keyhole had a strong effect on the intensity of the acoustical signals. Based on the experiments performed, an artificial neural network (ANN) was also constructed for the diagnosis of welding faults. The quality characterization of laser welds, based on acoustical signals, has been also studied in [51,114] and [52], integrating ANN and multiple regression methods and investigating the penetration as a quality measure. 

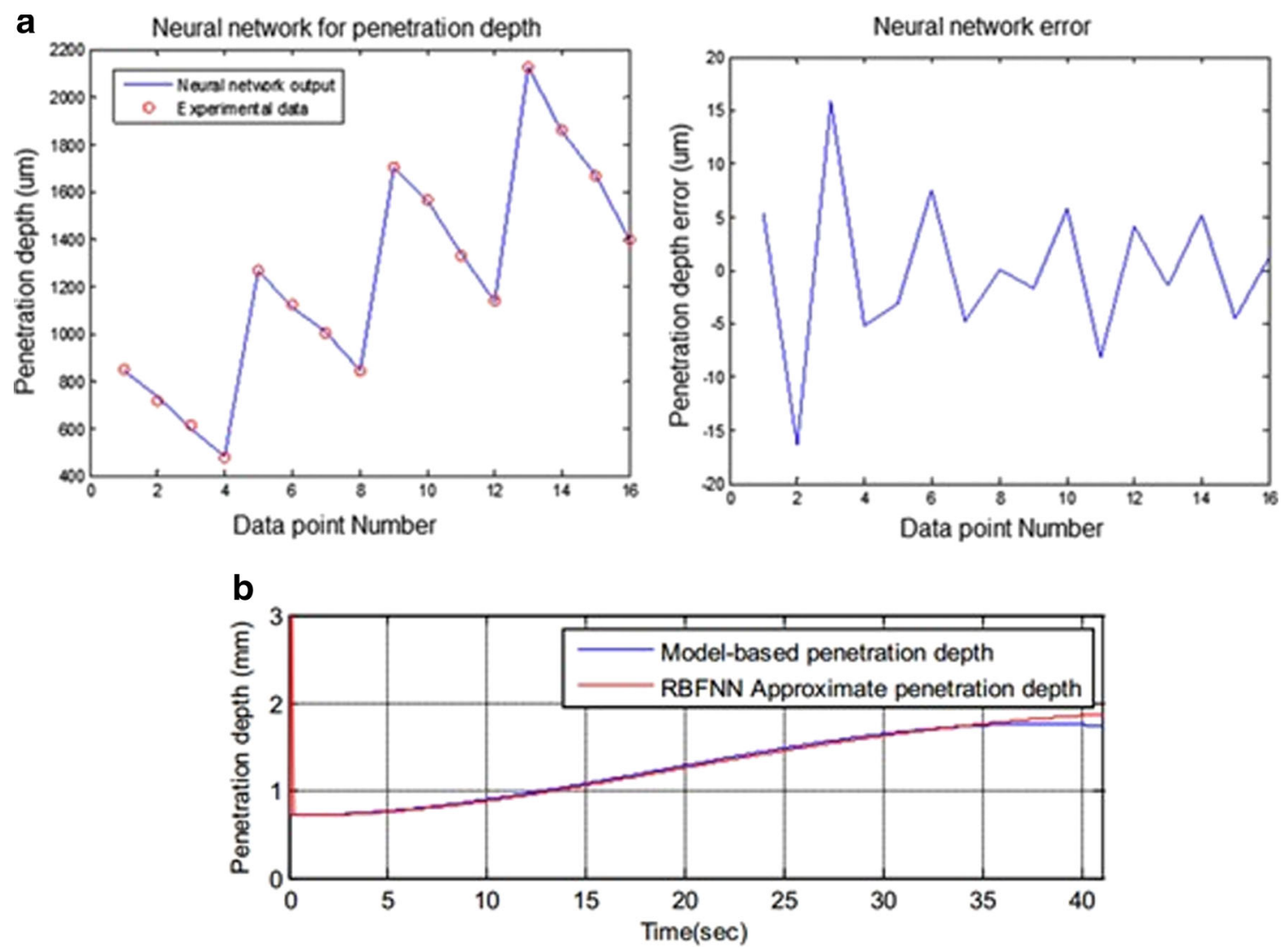

Fig. 10 a Static NN results for penetration depth. b Dynamic NN results for changing laser power [112]

Another interesting approach that implements a different inspection technology is introduced in [115]. Authors describe a fuzzy pattern recognition-based system for monitoring the laser weld quality. Plasma and spatter were measured by two photodiode sensors and used for the estimation of the weld quality. The welds were classified as optimal heat input, slightly low heat input, low heat input, and misalignment of focus, compared with reference values obtained from experiments. By extending their study, the same authors developed laser weld quality methods that implemented ANN and regression models in [116] and [117]. Plasma and spatter were also the phenomena measured for the identification of good or bad welds.

It is clear from the papers cited above that classification modeling for the status of the welding quality has become a research focus. Several studies have proposed alternatives, based on a different sensing feedback, aiming to establish in-process quality assessment techniques and effective adaptive control systems.

Paper's summary table The summary table presented below aims to provide information concentrated on the publications cited in this paper. The columns depict the different monitoring techniques implemented for the inspection of the weld defects, while the rows refer to the physical phenomena observed with the particular sensors, the identifiable defects, the cost, and the limitations of each technology as well as the related citations. In this way, the reader can easily match the monitoring technologies with the laser welding phenomena and the defects that can be directly or indirectly correlated with the sensing feedback. Additionally, the reader can look up relevant publications and extract additional information. Generally, it was observed that inner defects such as cracks, pores, and outer formations, namely, humping, were detected from the temperature field and the melt pool with the use of thermal or/and vision cameras as well as spectrometers and $\mathrm{x}$ ray devices. On the other hand, the penetration depth and width of a weld, as well as the undercuts and blowouts, have been extracted not only from the use of cameras but also from acoustic and optical sensors such as photodiodes, pyrometers, and spectrometers, while the monitored phenomena were the plasma plume, spatters, work-piece, and reflected laser beam energy. Finally, from the reviewed application, the fact obtained is that camera solutions were expensive with a demanding setup and a relatively low sampling rate, while the acoustic and optical sensors were more easily integrated. However, the acoustic and optical sensors were insufficient to capture critical defects in contrast with the cameras (even indirectly), while the sensors could identify only specific characteristics of the process. 


\section{Post-process quality assessment of laser welding}

Post-process quality inspection is usually performed by wellknown techniques such as eddy current, ultrasonic, visual, or radiographic testing. The particular methods of inspection can verify compliance between standards and the weld quality, through the examination of the surface and the subsurface of the weld and the surrounding base material. The effort for automated test procedures in these techniques is very high, and an online solution is not possible to be implemented. Thus, the quality feedback loop is larger compared with the online solutions. For this reason, most of the studies presented in this section concern the application of these methods in post-process inspection. However, some papers are also cited in which focus is given to the development of real-time automatic inspection algorithms, based on x-ray imaging.

\subsection{Ultrasonic}

Ultrasonic inspection methods involve generation of ultrasonic waves, which then interact with the weld. Internal defects cause the incident wave to reflect and or diffract. These waves are then detected and analyzed. Passini [118] investigated and published an ultrasonic phased array inspection for the detection of defects in thin aluminum laser beam-welded sheets. A correlation between this technique and the radiographic and metallographic inspections has also been performed. Among the conclusions obtained, the authors observed that when the attenuation of the ultrasonic waves was received separately for the base metal, it was possible to identify not only the welding line but also the presence of grouped pores. However, as no microcracks were found by metallographic inspection on the welded samples, it was not possible to be verified if the principle of ultrasonic wave attenuation could be applied to crack detection in the welding line. Moreover, the authors in [119] introduced a new ultrasonic technique, designed for the inline inspection of the laser welds of tailored blanks. The investigated application concerned a large-volume production process, and it was necessary that the defective blanks be immediately separated. The process integration also required an inspection speed of about $10 \mathrm{~m} / \mathrm{min}$ and a signal processing technique that could be easily automated at moderate costs. Thus, the ultrasonic technique's development was based on the application of guided ultrasonic (plate) waves with shear horizontal polarization, excited and detected by free electromagnetic acoustic transducers (EMATs). The principle behind the developed UT and the scanning probe that was used is illustrated in Fig. 11.

Using a non-contact electro-magnetic acoustic transducer placed on the opposite side of a Nd:YAG Qswitched pulse laser, which generates ultrasound, researchers in [120] have analyzed the signal in order to determine the time required for ultrasound to travel from the one end to the other [time of flight measurement (ToF)]. With this system, the authors were able to calculate weld geometry from indicating the weld quality. In a next stage, according to the paper, these data could be used as feedback for controlling a welding process. Similar approaches have been thoroughly investigated in the doctoral theses presented in [121] and [122]. Additionally, the hybrid EMAT system was deployed in [123], overcoming the problem of detecting very low-amplitude diffracted waves through the illumination of the surface with a laser beam, produced from a high-energy pulsed laser. The laser source was used in order to generate ultrasonic waves of relatively great amplitude.

However, according to [124], the ToF methods require accurate knowledge of the sound speed for the definition of geometric quantities. This is not a drawback for known uniform material temperature profiles, but the in-process use of such systems in a high-temperature environment is impossible, due to serious limitations on the accuracy of the measurements. a

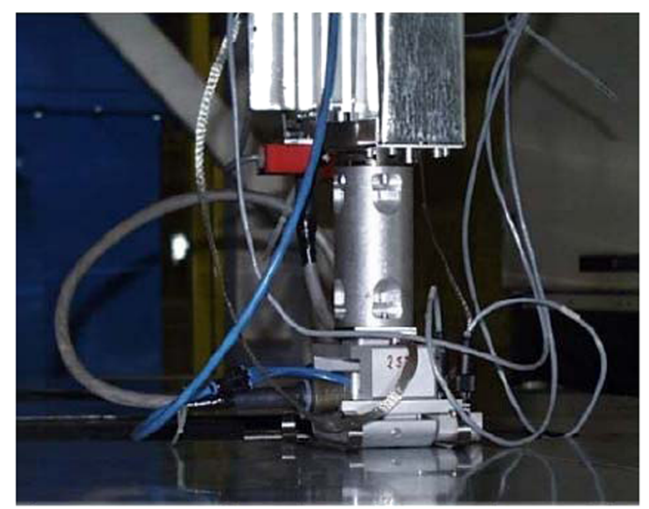

b Probe
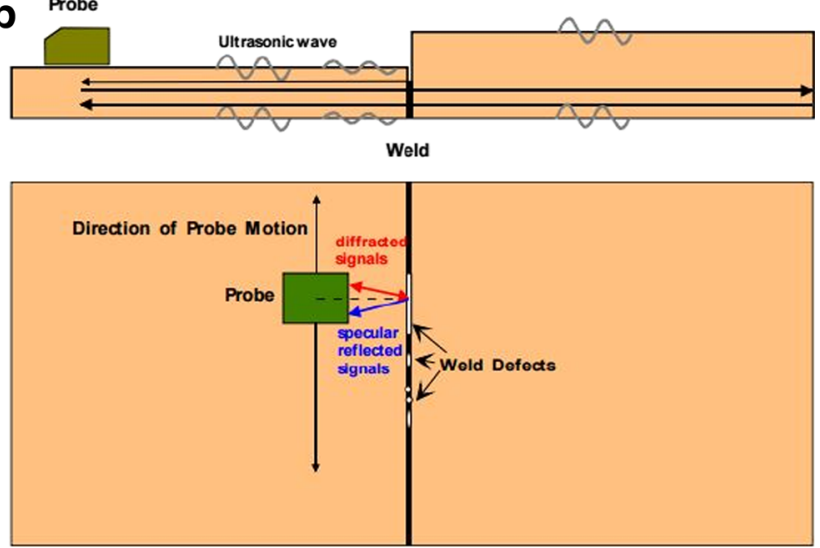

Fig. 11 a Electromagnetic acoustic transducers with probe holder scanning a weld. b Ultrasonic technique principal [119] 

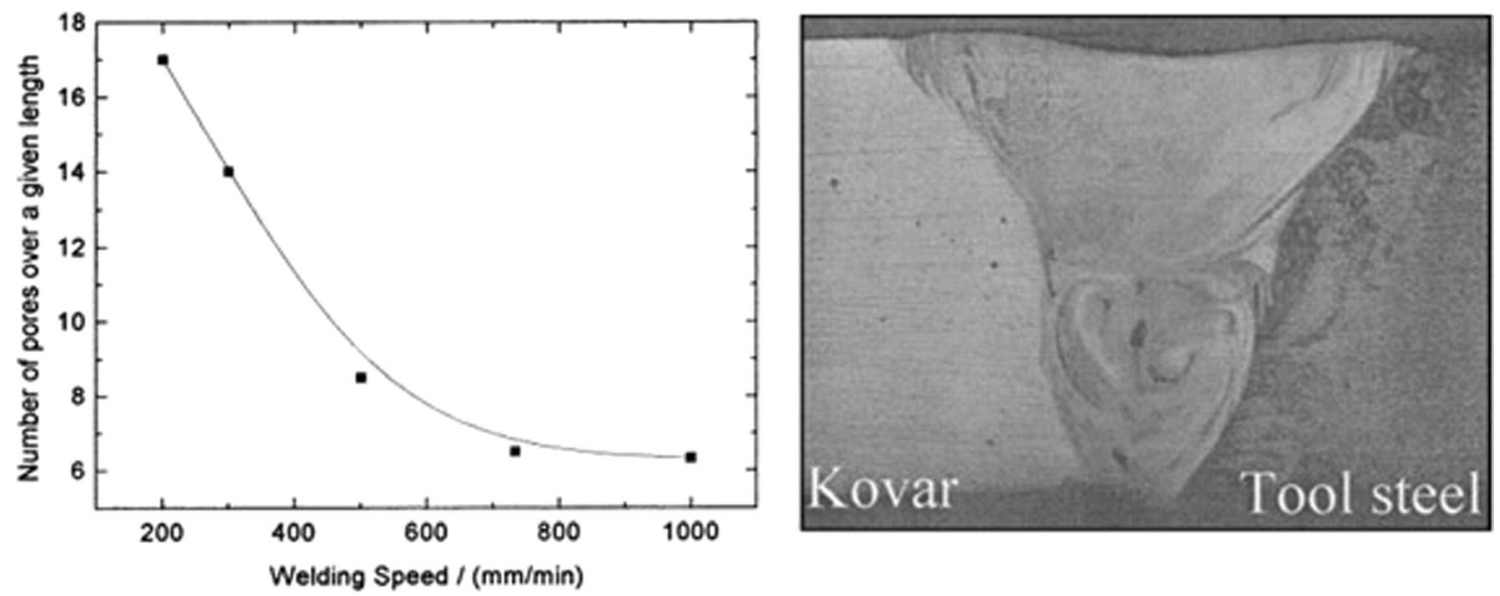

Fig. 12 Relation of porosity with welding speed (left). Cross section of dissimilar material joint (right) [125]

\subsection{X-ray radiography}

Radiography is based on the ability of $\mathrm{x}$-rays and gamma rays to pass through metal and other materials opaque to ordinary light, and produce photographic records of the transmitted radiant energy. All materials will absorb known amounts of this radiant energy, and therefore, $\mathrm{x}$-rays and gamma rays can be used in order to show discontinuities and inclusions within the opaque material. The permanent film record of the internal conditions will show the basic information by which weld soundness can be determined. The low speed and potential radiation hazards limit its use. The results in most cases require operator interpretation, and seldom is it used in automated environments. Additionally, x-ray techniques are very expensive due to the manipulation of the parts and the protection required; consequently, they cannot be applied to typical production cycles of a weld machine.

However, there are several studies which were investigated and improved radiography testing in laser welding processes. Indicatively, Mai and Spowage [125] investigated the porosity of dissimilar material joints by using $x$-ray imaging. Examination of porosity indicated clear trends, associated with the laser welding speed, while the weld pool geometry was also captured by the x-ray technique. Figure 12 presents the cross section of a joint and the effect of the welding speed on weld porosity and number of pores.

An interesting approach, based on x-ray images, is also described in [126]. The authors have presented a method of automatic defect recognition on the x-ray weld image, based on a support vector machine (SVM). In addition, in [127], a defect recognition approach was developed, on the basis of the $\mathrm{x}$-ray image processing techniques. The novelty with this study was the implementation of an effective method, based on the fuzzy theory. With the proposed algorithm, the images were filtered with the application of fuzzy reasoning via local image characteristics, aiming to detect small objects of low contrast. One step further, the x-ray imaging inspection technique was adopted by the authors in [128] in order to optimize the laser parameters with the evaluation of the identified defects. Finally, the paper presented in [129] described a method for the reconstruction of the 3D shape of the melt pool and the capillary of a laser keyhole welding process. Three different diagnostic methods, including x-ray, optical videography, and metallographic cross sections, were combined to acquire the three-dimensional data of the solidus-liquidus surface. A detailed description of the experimental setup and a discussion on different methods for the combination of the 2D data sets of the three different diagnostic methods with a 3D model were also given. The suggested method improved the understanding of the process fundamentals of laser welding and offered the possibility of calibrating or verifying computer-aided process simulations.

\subsection{Eddy current technique}

The eddy current systems use electromagnetism to provide surface inspection and a limited level of subsurface inspection (a few thousands of an inch). When an alternating current is applied to a coil, a magnetic field is developed in and around it. If an electrically conductive material is placed in the coil's dynamic magnetic field, electromagnetic induction will occur and eddy currents will be induced in the material. The eddy currents generate a secondary magnetic field that will oppose to the coil's primary magnetic field [130]. The conventional eddy current techniques are capable of detecting longitudinal and traverse surface cracks, the lack of fusion, the crater cracks, the pores, and other surface-breaking discontinuities. According to the research in [130], an eddy current method has been tested for detection and classification of defects in laser-welded seams. Defects and changes in material properties have resulted in changing eddy current signals. The eddy current data were pre-processed and assigned to the 


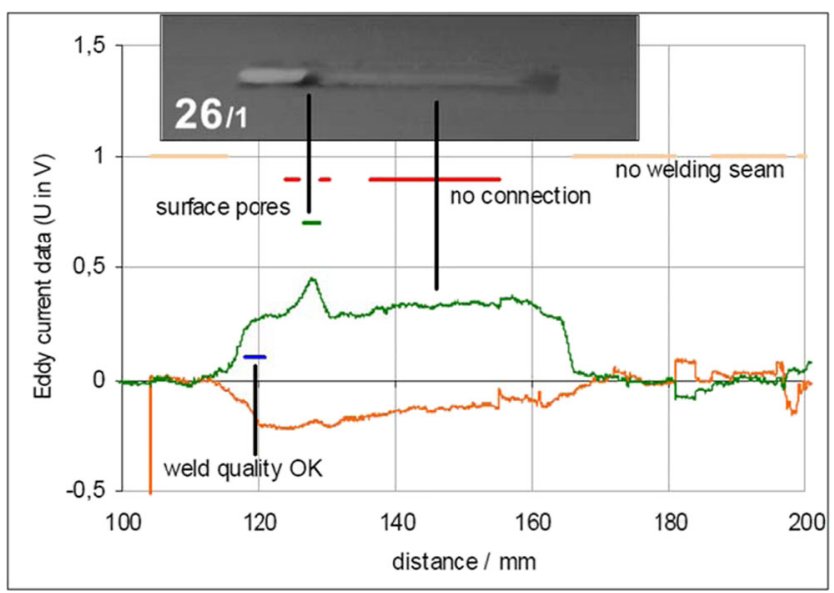

Fig. 13 Eddy current signal for reference sample (orange graph, weld quality $\mathrm{OK}$ ) and examined sample (green graph) versus distance [130] (color figure online)

characteristic areas of making reference to x-ray samples, in the impedance plane diagram. There were parts of satisfactory quality, with surface pores, lacking in connection as well as unwelded parts identified. The results were in good agreement with reference methods, such as radiography and metallography. Figure 13 illustrates the evaluation results of a laser welding seam which shows surface pores and areas without connection of the joining plates. In the same pattern, but focusing only on crack defects for identification, the authors in [131] firstly developed a vision-based system for an automated inspection of surface cracks in materials. Afterwards, the magnetic particle inspection method was used in order to reveal cracks in ferromagnetic materials. For each crack, the average length and width were calculated through the calibration of the vision system for its conversion from pixels into millimeters. The width measurements, before and after the test, were also in agreement, indicating that the system had made valid measurements of the crack size.

A modification to the technique has led to the establishment of the eddy current array (ECA) technology, which enhanced its capabilities with the use of several coils in a single probe, in a cooperative sequence for the prevention of mutual interference. The sequence can provide a wide and complete scan of the surface. The coils are designed to have the required impedance and penetration for the accurate inspection of the target material. In this regard, a study conducted for the inspection of laser welds, implementing the array eddy current technique, has been presented in [132]. The authors have created three groups in order to evaluate the weld quality. The experiments were classified as good $(\mathrm{G})$, lack of penetration (LOP), and full penetration. The weld defects were matched with the current signal, and a more detailed analysis could be compared with the simple eddy current technique. According to the conclusions of the study, the advanced array eddy current technique demonstrated excellent capabilities to detect through the image typical laser welds' flaws with length (less than $2 \mathrm{~mm}$ and depth less than $1 \mathrm{~mm}$ (underfill profile)). Finally, it was concluded that the technique could be easily automated for fast inline, but post-process inspection and the control of the laser welding process.

Despite the advantages of the eddy current technique (minimal testing time, measurements without human intervention, non-destructive, contactless, minimum part preparation), there are drawbacks that limit its extended use: The technique applies only to conductive materials, the surface has to be accessible to the probe, the surface finish and roughness may interfere, and the reference standards are necessary for set up. Finally, eddy current technique is often used in conjunction with other inspection methods, due to its difficulty in detecting some critical defects and its limitation to penetrating the test material.

\section{Discussion and future outlook}

In this paper, a critical review has been made on the previous efforts for the improvement and investigation of new methods, techniques, and modeling approaches for quality assessment in laser welding. The paper has been separated into two main sections, based on the time that the inspection and assessment of the laser welds took place. Furthermore, the corresponding papers have been deployed according to the operating principle used for the monitoring of the process. Moreover, the correlation of process parameters and quality metrics was another aspect that was taken into consideration. Therefore, analytical (also numerically solved) and empirical approaches were investigated and included in the study.

From what has been cited, it can be concluded that for inprocess quality assessment techniques, non-invasive optical sensing is considered being the ideal real-time monitoring technology for laser welding. Specifically, thermal and vision cameras provide a more complete view of the laser welds as far as the temperature field and the spatial information is concerned. However, the dependence of the image-based temperature measurements on material properties, namely, emissivity, has raised some issues as regards the detailed study of all the phenomena that occur during the melting, evaporation, and solidification phases in laser welding. However, as it has been shown above, several publications have overcome this drawback, and lately, there is an upgraded interest of the researchers who seem to focus on creating and establishing industrial multi-spectral and multi-modal solutions [133, 134]. The idea is that the device will be able to capture a wide range of infrared spectrum enabling the monitoring of different magnitudes in different spectral bands.

Additionally, the review has pointed out that the development of modeling in order to correlate measured magnitudes and process parameters during laser welding with quality 
metrics has been extensively investigated in the literature. Focus has been given to the development of models with targeting the estimation of the melt pool and the keyhole's evolution under specific process parameters, while in several attempts, semi-empirical models led to the correlation of the temperature field and the melt pool evolution with the existence of defects. On the other hand, empirical modeling is a key tool that has to be further integrated into real-time control and quality assessment systems, mainly due to the quality prediction and re-training capabilities that the machine learning and classification techniques can provide to the system, fed by previous labeled data.

Taking into account the above, it is obvious that the development of a quality assessment system with cognitive characteristics can be the most interesting and challenging field, for future research in laser-based manufacturing in general, and not only in laser welding. The implementation of machine learning techniques can interfere with control systems, and based on experimental modeling approaches, they can predict defects and assure the quality in the products. The implementation and integration of such systems will lead to a sustainable, modular, and flexible manufacturing.

Acknowledgements This work is under the framework of EU Project MAShES. This project has received funding from the European Union's Horizon 2020 research and innovation program under grant agreement No. 637081. The dissemination of results herein reflects only the authors' view, and the Commission is not responsible for any use that may be made of the information it contains.

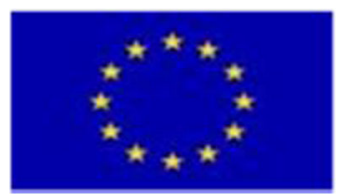

Open Access This article is distributed under the terms of the Creative Commons Attribution 4.0 International License (http:// creativecommons.org/licenses/by/4.0/), which permits unrestricted use, distribution, and reproduction in any medium, provided you give appropriate credit to the original author(s) and the source, provide a link to the Creative Commons license, and indicate if changes were made.

\section{References}

1. Chryssolouris G, Papakostas N, Mavrikios D (2008) A perspective on manufacturing strategy: produce more with less. CIRP J Manuf Sci Technol 1(1):45-52

2. Chryssolouris George (2013) Manufacturing systems: theory and practice. Springer Science \& Business Media

3. Tsoukantas $\mathrm{G}$ et al (2007) On optical design limitations of generalized two-mirror remote beam delivery laser systems: the case of remote welding. Int J Adv Manuf Technol 32(9-10):932-941
4. Chryssolouris ELKE (2013) Laser machining: theory and practice. Springer Science \& Business Media

5. Stournaras A, Stavropoulos P, Salonitis K, Chryssolouris G (2008) Laser process monitoring: a critical review, (ICMR 08), 6th International Conference on Manufacturing Research, Uxbridge, pp. $425-435$

6. Kaierle S (2008) Process monitoring and control of laser beam welding. Laser Technik Journal 5(3):41-43

7. Katayama Seiji, and Kawahito Yousuke (2009) Elucidation of phenomena in high-power fiber laser welding and development of prevention procedures of welding defects. SPIE LASE: Lasers and Applications in Science and Engineering. International Society for Optics and Photonics

8. Shao Jiaqing and Yan Yong (2005) Review of techniques for online monitoring and inspection of laser welding. Journal of Physics: Conference Series. Vol. 15. No. 1. IOP Publishing

9. Zhao H, DebRoy T (2001) Pore formation during laser beam welding of die-cast magnesium alloy AM60B-mechanism and remedy. Weld J 80(8):204-210

10. Pastor M, et al. (1999) Porosity, underfill and magnesium lose during continuous wave Nd: YAG laser welding of thin plates of aluminum alloys 5182 and 5754. WELDING JOURNAL-NEW YORK- 78: 207-s

11. Madison JD, Aagesen LK (2012) Quantitative characterization of porosity in laser welds of stainless steel. Scr Mater 67(9):783-786

12. Norris JT et al (2011) Effects of laser parameters on porosity formation: investigating millimeter scale continuous wave Nd: YAG laser welds. Weld J 90:198-203

13. Kamimuki $\mathrm{K}$ et al (2002) Prevention of welding defect by side gas flow and its monitoring method in continuous wave Nd: YAG laser welding. Journal of Laser applications 14(3):136-145

14. Harooni M, Carlson B, Kovacevic R (2014) Detection of defects in laser welding of AZ31B magnesium alloy in zero-gap lap joint configuration by a real-time spectroscopic analysis. Opt Lasers Eng 56:54-66

15. Katayama Seiji, Mizutani Masami, Matsunawa Akira (2003) Development of porosity prevention procedures during laser welding." Proc. SPIE. Vol. 4831

16. Rodil SS et al (2010) Laser welding defects detection in automotive industry based on radiation and spectroscopical measurements. Int J Adv Manuf Technol 49(1-4):133-145

17. Sheikhi M, Malek Ghaini F, Assadi H (2015) Prediction of solidification cracking in pulsed laser welding of 2024 aluminum alloy. Acta Mater 82:491-502

18. Lippold JC (1994) Solidification behavior and cracking susceptibility of pulsed-laser welds in austenitic stainless steels. Welding Journal Including Welding Research Supplement 73(6):129s

19. Ya Wei (2015) Laser materials interactions during cladding: analyses on clad formation, thermal cycles, residual stress and defects. Universiteit Twente

20. Bergmann JP, Bielenin M, Feustel T (2015) Aluminum welding by combining a diode laser with a pulsed Nd: YAG laser. Welding in the World 59(2):307-315

21. Gratzke U et al (1992) Theoretical approach to the humping phenomenon in welding processes. J Phys D Appl Phys 25(11):1640

22. Ilar T et al (2012) Root humping in laser welding - an investigation based on high speed imaging. Phys Procedia 39:27-32

23. Schempp P, et al. (2013) Influence of alloy and solidification parameters on grain refinement in aluminum weld metal due to inoculation. Trends in Welding Research 2012: Proceedings of the 9 th International Conference. ASM International

24. Gade R, Moeslund TB (2014) Thermal cameras and applications: a survey. Mach Vis Appl 25(1):245-262

25. Tadamalle AP (2012) Review of real-time temperature measurement for process monitoring of laser conduction welding. Eng Sci Technol An Int J 2(5):946-950 
26. Speka $\mathrm{M}$ et al (2008) The infrared thermography control of the laser welding of amorphous polymers. NDT \& E International 41(3):178-183

27. Chen Z, Gao X (2014) Detection of weld pool width using infrared imaging during high-power fiber laser welding of type 304 austenitic stainless steel. Int J Adv Manuf Technol 74(9-12):12471254

28. Bardin F et al (2005) Process control of laser conduction welding by thermal imaging measurement with a color camera. Appl Opt 44(32):6841-6848

29. Bardin F et al (2005) Closed-loop power and focus control of laser welding for full-penetration monitoring. Appl Opt 44(1):13-21

30. You DY, Gao XD, Katayama S (2014) Review of laser welding monitoring. Sci Technol Weld Join 19(3):181-201

31. Hutter Franz X., et al. (2009) A $0.25 \mu \mathrm{m}$ logarithmic CMOS imager for emissivity-compensated thermography. Solid-State Circuits Conference-Digest of Technical Papers, 2009. ISSCC 2009. IEEE International. IEEE

32. Köhler H, Thomy C, Vollertsen F (2016) Contact-less temperature measurement and control with applications to laser cladding. Welding in the World 60(1):1-9

33. Kim C-H, Ahn D-C (2012) Coaxial monitoring of keyhole during Yb: YAG laser welding. Opt Laser Technol 44(6):1874-1880

34. Huang W, Kovacevic R (2011) A laser-based vision system for weld quality inspection. Sensors 11(1):506-521

35. Saeed G, Zhang YM (2007) Weld pool surface depth measurement using a calibrated camera and structured light. Meas Sci Technol 18(8):2570

36. Zhang Y, Gao X (2014) Analysis of characteristics of molten pool using cast shadow during high-power disk laser welding. Int J Adv Manuf Technol 70(9-12):1979-1988

37. Abt $\mathrm{F}$ et al (2011) Camera based closed loop control for partial penetration welding of overlap joints. Phys Procedia 12:730-738

38. Kawahito Y, Mizutani M, Katayama S (2007) Investigation of high-power fiber laser welding phenomena of stainless steel. TRANSACTIONS-JWRI 36(2): 11

39. Tenner $\mathrm{F}$ et al (2015) Experimental approach for quantification of fluid dynamics in laser metal welding. Journal of Laser Applications 27(S2):S29003

40. Gao X-d, Qian WEN, Katayama S (2013) Analysis of high-power disk laser welding stability based on classification of plume and spatter characteristics. Trans Nonferrous Metals Soc China 23(12): 3748-3757

41. Tenner F et al (2015) Analysis of the correlation between plasma plume and keyhole behavior in laser metal welding for the modeling of the keyhole geometry. Opt Lasers Eng 64:32-41

42. Volpp Joerg, Srowig Jennifer, Vollertsen Frank. (2016) Spatters during laser deep penetration welding with a bifocal optic. Advanced materials research. Vol. 1140. Trans Tech Publications

43. Purtonen T, Kalliosaari A, Salminen A (2014) Monitoring and adaptive control of laser processes. Phys Procedia 56:1218-1231

44. Voelkel DD, Mazumder J (1990) Visualization of a laser melt pool. Appl Opt 29(12):1718-1720

45. Al-Habaibeh A, et al. (2004) A novel approach for quality control system using sensor fusion of infrared and visual image processing for laser sealing of food containers. Measurement Science and Technology 15.10

46. von Witzendorff $\mathrm{P}$ et al (2015) Using pulse shaping to control temporal strain development and solidification cracking in pulsed laser welding of 6082 aluminum alloys. J Mater Process Technol 225:162-169

47. Dorsch Friedhelm, et al. (2012) NIR-camera-based online diagnostics of laser beam welding processes. SPIE LASE. International Society for Optics and Photonics

48. Dorsch F, Braun H, Keßler S, Magg W (2012) Process sensor systems for laser beam welding. Laser Technik J 9:24-28
49. Zeng $\mathrm{H}$ et al (2001) Wavelet analysis of acoustic emission signals and quality control in laser welding. Journal of Laser Applications 13(4):167-173

50. Li L (2002) A comparative study of ultrasound emission characteristics in laser processing. Appl Surf Sci 186(1):604-610

51. Lee S, Ahn S, Park C (2014) Analysis of acoustic emission signals during laser spot welding of SS304 stainless steel. J Mater Eng Perform 23(3):700-707

52. Kercel Stephen W, et al. (1999) In-process detection of weld defects using laser-based ultrasound. Proc. SPIE. Vol. 3852

53. Lott $P$ et al (2011) Design of an optical system for the in situ process monitoring of selective laser melting (SLM). Phys Procedia 12:683-690

54. Vallejo, David Diego (2014) Spectroscopic investigations of plasma emission induced during laser material processing. epubli

55. Webster PJL et al. (2015) Three-dimensional, multi-factor monitoring and control of laser keyhole welding by inline coherent imaging

56. Papazoglou DG, Papadakis V, Anglos D (2004) In situ interferometric depth and topography monitoring in LIBS elemental profiling of multi-layer structures. J Anal At Spectrom 19(4):483-488

57. Park YW et al (2002) Real time estimation of CO 2 laser weld quality for automotive industry. Opt Laser Technol 34(2):135-142

58. Zhang X et al (2004) Relationship between weld quality and optical emissions in underwater Nd: YAG laser welding. Opt Lasers Eng 41(5):717-730

59. You D, Gao X, Katayama S (2013) Multiple-optics sensing of high-brightness disk laser welding process. NDT \& E International 60:32-39

60. Kaplan Alexander FH, Norman Peter, Eriksson Ingemar. (2009) Analysis of the keyhole and weld pool dynamics by imaging evaluation and photodiode monitoring. Proceedings of LAMP2009the 5th International Congress on Laser Advanced Materials Processing

61. Sanders PG et al (1998) Real-time monitoring of laser beam welding using infrared weld emissions. Journal of laser Applications 10(5):205-211

62. Sanders PG, et al. (1997) Capabilities of infrared weld monitor. No. ANL/TD/CP-93200; CONF-971149-. Argonne National Lab., IL (United States)

63. Kim J-T et al (2003) Laser welding quality monitoring with an optical fiber system. Journal of the Optical Society of Korea 7(3): 193-196

64. Sibillano $\mathrm{T}$ et al (2006) Correlation spectroscopy as a tool for detecting losses of ligand elements in laser welding of aluminium alloys. Opt Lasers Eng 44(12):1324-1335

65. Mrňa L et al (2012) Feedback control of laser welding based on frequency analysis of light emissions and adaptive beam shaping. Phys Procedia 39:784-791

66. Sibillano T et al (2007) Real-time monitoring of laser welding by correlation analysis: the case of AA5083. Opt Lasers Eng 45(10): 1005-1009

67. Rizzi D et al (2011) Spectroscopic, energetic and metallographic investigations of the laser lap welding of AISI 304 using the response surface methodology. Opt Lasers Eng 49(7):892-898

68. Konuk AR et al (2011) Process control of stainless steel laser welding using an optical spectroscopic sensor. Phys Procedia 12: 744-751

69. Sebestova $\mathrm{H}$ et al (2012) Non-destructive real time monitoring of the laser welding process. J Mater Eng Perform 21(5):764-769

70. Sibillano T et al (2012) Closed loop control of penetration depth during CO2 laser lap welding processes. Sensors 12(8):1107711090

71. Zaeh MF, Huber S (2011) Characteristic line emissions of the metal vapor during laser beam welding. Prod Eng 5(6):667-678 
72. Smurov Igor (2001) Pyrometry applications in laser machining. Laser-assisted microtechnology 2000. International Society for Optics and Photonics

73. Bertrand P, Smurov I, Grevey D (2000) Application of near infrared pyrometry for continuous Nd: YAG laser welding of stainless steel. Appl Surf Sci 168(1):182-185

74. Smurov Igor (2007) Laser process optical sensing and control." IV International WLT-Conference on Lasers in Manufacturing

75. Doubenskaia M, et al. (2007) On-line optical monitoring of Nd: YAG laser lap welding of Zn-coated steel sheets. IV International WLT-Conference on Lasers in Manufacturing

76. Zhang $\mathrm{Pu}$, et al. (2008) Real-time monitoring of laser welding based on multiple sensors. Control and Decision Conference, 2008. CCDC 2008. Chinese. IEEE

77. Farson D, Ali A, SANG YAN (1998) Relationship of optical and acoustic emissions to laser weld penetration. Weld J 77(4):142-s

78. Kamimuki $\mathrm{K}$ et al (2003) Behavior of monitoring signals during detection of welding defects in YAG laser welding. Study of monitoring technology for YAG laser welding (report 2). Weld Int 17(3):203-210

79. Nakamura $\mathrm{S}$ et al (2000) Detection technique for transition between deep penetration mode and shallow penetration mode in CO2 laser welding of metals. J Phys D Appl Phys 33(22):2941

80. You D, Gao X, Katayama S (2015) A novel stability quantification for disk laser welding by using frequency correlation coefficient between multiple-optics signals. Mechatronics, IEEE/ASME Transactions on 20(1):327-337

81. Norman Peter, et al. (2008) Correlation between photodiode monitoring and high speed imaging of the dynamics causing laser welding defects. International Congress on Applications of Lasers \& Electro-Optics: 20/10/2008-23/10/2008. Laser institute of America

82. Norman P, Engström H, Kaplan AFH (2008) Theoretical analysis of photodiode monitoring of laser welding defects by imaging combined with modelling. J Phys D Appl Phys 41(19):195502

83. Mickel PM, Kuhl M, Seidel M (2007) Quality and process control of laser welding using multisensory systems and methods of pattern recognition. Proc. LANE, Germany: 957-966

84. Clijsters $\mathrm{S}$ et al (2014) In situ quality control of the selective laser melting process using a high-speed, real-time melt pool monitoring system. Int J Adv Manuf Technol 75(5-8):1089-1101

85. Vänskä $\mathrm{M}$ et al (2013) Effects of welding parameters onto keyhole geometry for partial penetration laser welding. Phys Procedia 41: 199-208

86. Du Dong, et al. (2007) Automatic inspection of weld defects with $\mathrm{X}$-ray real-time imaging. Robotic welding, intelligence and automation. Springer Berlin Heidelberg. 359-366

87. Katayama S, Kawahito Y, Mizutani M (2007) Collaboration of physical and metallurgical viewpoints for understanding and process development of laser welding. ICALEO 2007 Congress Proceedings (Proceedings of the 26th International Congress on Applications of Lasers \& Electro-Optics), LIA, Orlando

88. Naito Y, Mizutani M, Katayama S (2006) Effect of oxygen in ambient atmosphere on penetration characteristics in single yttrium-aluminum-garnet laser and hybrid welding. Journal of laser applications 18(1):21-27

89. Chryssolouris G, Yablon A (1993) Depth prediction in laser machining with the aid of surface temperature measurements. CIRP Annals-Manufacturing Technology 42(1):205-207

90. Lankalapalli KN, Tu JF, Gartner M (1996) A model for estimating penetration depth of laser welding processes. J Phys D Appl Phys 29(7): 1831

91. Dowden J, Kapadia P (1995) A mathematical investigation of the penetration depth in keyhole welding with continuous $\mathrm{CO} 2$ lasers. J Phys D Appl Phys 28(11):2252
92. Lampa C et al (1997) An analytical thermodynamic model of laser welding. J Phys D Appl Phys 30(9):1293

93. Volpp J, Vollertsen F (2016) Keyhole stability during laser welding - part I: modeling and evaluation. Prod Eng 10(4-5): 443-457

94. Kim J-D (1990) Prediction of the penetration depth in laser beam welding. KSME journal 4(1):32-39

95. Kazemi K, Goldak JA (2009) Numerical simulation of laser full penetration welding. Comput Mater Sci 44(3):841-849

96. Pastras $\mathrm{G}$ et al (2015) A numerical approach to modeling keyhole laser welding. Int J Adv Manuf Technol 78(5-8):723-736

97. GuoMing H, Jian Z, JianQang L (2007) Dynamic simulation of the temperature field of stainless steel laser welding. Mater Des 28(1):240-245

98. Zhao $\mathrm{S}$ et al (2011) Numerical simulation and experimental investigation of laser overlap welding of Ti6Al4V and 42CrMo. J Mater Process Technol 211(3):530-537

99. Abderrazak K et al (2009) Numerical and experimental study of molten pool formation during continuous laser welding of AZ91 magnesium alloy. Comput Mater Sci 44(3):858-866

100. Mishra S, Chakraborty S, DebRoy T (2005) Probing liquation cracking and solidification through modeling of momentum, heat, and solute transport during welding of aluminum alloys. J Appl Phys 97(9):094912

101. Pang S, Chen W, Wang W (2014) A quantitative model of keyhole instability induced porosity in laser welding of titanium alloy. Metall Mater Trans A 45(6):2808-2818

102. Zhao H, DebRoy T (2003) Macroporosity free aluminum alloy weldments through numerical simulation of keyhole mode laser welding. J Appl Phys 93(12):10089-10096

103. Acherjee B et al (2011) Application of grey-based Taguchi method for simultaneous optimization of multiple quality characteristics in laser transmission welding process of thermoplastics. Int J Adv Manuf Technol 56(9-12):995-1006

104. Olabi AG et al (2006) An ANN and Taguchi algorithms integrated approach to the optimization of CO 2 laser welding. Adv Eng Softw 37(10):643-648

105. Anawa EM, Olabi A-G (2008) Using Taguchi method to optimize welding pool of dissimilar laser-welded components. Opt Laser Technol 40(2):379-388

106. Pan LK et al (2005) Optimization of Nd: YAG laser welding onto magnesium alloy via Taguchi analysis. Opt Laser Technol 37(1): 33-42

107. Casalino G, Curcio F, Memola Capece Minutolo F (2005) Investigation on Ti6Al4V laser welding using statistical and Taguchi approaches. J Mater Process Technol 167(2):422-428

108. Tzeng Y-F (2000) Process characterization of pulsed Nd: YAG laser seam welding. Int J Adv Manuf Technol 16(1):10-18

109. Park YW, Rhee S (2008) Process modeling and parameter optimization using neural network and genetic algorithms for aluminum laser welding automation. Int J Adv Manuf Technol 37(9-10): 1014-1021

110. Jeng J-Y, Mau T-F, Leu S-M (2000) Prediction of laser butt joint welding parameters using back propagation and learning vector quantization networks. J Mater Process Technol 99(1):207-218

111. Naso D, Turchiano B, Pantaleo P (2005) A fuzzy-logic based optical sensor for online weld defect-detection. IEEE transactions on Industrial Informatics 1(4):259-273

112. Luo M, Shin YC (2015) Estimation of keyhole geometry and prediction of welding defects during laser welding based on a vision system and a radial basis function neural network. Int $\mathrm{J}$ Adv Manuf Technol 81(1-4):263-276

113. Luo H et al (2005) Application of artificial neural network in laser welding defect diagnosis. J Mater Process Technol 170(1):403-411

114. Huang W, Kovacevic R (2011) A neural network and multiple regression method for the characterization of the depth of weld 
penetration in laser welding based on acoustic signatures. J Intell Manuf 22(2):131-143

115. Park H, Rhee S, Kim D (2001) A fuzzy pattern recognition based system for monitoring laser weld quality. Meas Sci Technol 12(8): 1318

116. Park H, Rhee S (1999) Analysis of mechanism of plasma and spatter in CO 2 laser welding of galvanized steel. Opt Laser Technol 31(2):119-126

117. Park H, Rhee S (1999) Estimation of weld bead size in CO2 laser welding by using multiple regression and neural network. Journal of Laser Applications 11(3):143-150

118. Passini A et al (2011) Ultrasonic inspection of AA6013 laser welded joints. Mater Res 14(3):417-422

119. Salzburger HJ, Mohrbacher H (2002) In-line quality control of laser welds of tailored blanks by couplant free ultrasonic inspection. European Federation for Non-Destructive Testing (EFNDT), European Conference on Nondestructive Testing (8)

120. Miller M et al (2002) Development of automated real-time data acquisition system for robotic weld quality monitoring. Mechatronics 12(9):1259-1269

121. Kita Akio (2005) Measurement of weld penetration depth using non-contact ultrasound methods

122. Rogge Matthew Douglas (2009) In-process sensing of weld penetration depth using non-contact laser ultrasound system

123. Dixon S, Edwards C, Palmer SB (1999) A laser-EMAT system for ultrasonic weld inspection. Ultrasonics 37(4):273-281

124. Mi B, Ume C (2006) Real-time weld penetration depth monitoring with laser ultrasonic sensing system. J Manuf Sci Eng 128(1):280286
125. Mai TA, Spowage AC (2004) Characterization of dissimilar joints in laser welding of steel-kovar, copper-steel and copper-aluminum. Mater Sci Eng A 374(1):224-233

126. Zhang Xiao-Guang, Xu Jian-Jian, Ge Guang-Ying (2004) Defects recognition on X-ray images for weld inspection using SVM. Machine Learning and Cybernetics, 2004. Proceedings of 2004 International Conference on. Vol. 6. IEEE

127. Lashkia V (2001) Defect detection in X-ray images using fuzzy reasoning. Image Vis Comput 19(5):261-269

128. Fu Y et al (1998) Laser alloying of aluminum alloy AA 6061 with $\mathrm{Ni}$ and $\mathrm{Cr}$. Part 1. Optimization of processing parameters by X-ray imaging. Surf Coat Technol 99(3):287-294

129. Boley $\mathrm{M}$ et al (2013) X-ray and optical videography for 3D measurement of capillary and melt pool geometry in laser welding. Phys Procedia 41:488-495

130. Zosch Antje, Seidel Martin (2006) Nondestructive testing of laser welded lap seams by eddy current technique, ECNDT

131. Ho SK, White RM, Lucas J (1990) A vision system for automated crack detection in welds. Meas Sci Technol 1(3):287

132. Todorov E, et al. (2013) Inspection of laser welds with array eddy current. AIP Conference Proceedings. Vol. 1511

133. Gilblas R, et al. (2011) Thermoreflectometry: a new system to determine the true temperature fields on surface with unknown emissivity. SPIE Defense, Security, and Sensing. International Society for Optics and Photonics

134. Hagen N, Kudenov MW (2013) Review of snapshot spectral imaging technologies. Opt Eng 52(9):090901-090901 